\title{
THE TECTONOPHYSICAL RESEARCHES OF THE SEMISAMSKAYA ANTICLINE (NORTH-WESTERN CAUCASUS FOLD AND THRUST BELT)
}

\section{A. V. Marinin}

The Schmidt Institute of Physics of the Earth RAS, Moscow, Russia

Abstract: Structural paragenetic and cataclastic analysis methods were applied to study tectonic fracturing within one of the folds of the southern wing of the North-Western Caucasus fold-and-thrust belt. The object of the study was the Semisamskaya anticline (Fig. 1 and 2) comprising the Upper Cretaceous and Paleogenic layered terrigenic-carbonate sediments that contain various well-developed geological indicators of palaeostresses (Fig. 3, 5, 7, and 9).

In the folded structure under study, a paragenesis is revealed which is associated with the effect of sub-horizontal minimum compression (deviator extension) stresses of the north-western orientation (NW 320 $)$ and traced by detached normal fault systems striking in the north-eastern direction (Fig. 6, 8, 10,11, and 17). Upthrust-overthrust systems of the northwestern strike (NW-SE), which are of importance for the whole folded structure of the North-Western Caucasus, are mainly manifested in the wings of the Semisamskaya anticline (Fig. 6, 12, and 13).

The overall field of stresses related to formation of the folded structure is significantly variable as evidenced by the pattern of local parameters of the paleostress field, which are calculated by the cataclastic analysis method (Figure 15, 16, and 17).

It is established that the geodynamic regime within the anticline is considerably variable by types (Fig. 18). Areas with horizontal extension in the axial part of the fold are replaced by areas of horizontal compression at its wings (Fig. 19).

Key words: paleostress, state of local stresses, tectonic regime, fold, anticline, tension gashes, normal fault, reverse fault, thrust fault, slickenside.

Recommended by Yu.L. Rebetsky

Citation: Marinin A.V. 2013. The tectonophysical researches of the Semisamskaya anticline (North-Western Caucasus fold and thrust belt). Geodynamics \& Tectonophysics 4 (4), 461-484. doi:10.5800/GT-2013-4-4-0113.

\section{ТЕКТОНОФИЗИЧЕСКИЕ ИССЛЕДОВАНИЯ СЕМИСАМСКОЙ АНТИКЛИНАЛИ (СЕВЕРО-ЗАПАДНЫЙ КАВКАЗ)}

\author{
А. В. Маринин \\ Институт физики Земли им. О.Ю. Шмидта РАН, Москва, Россия
}

Аннотация: Исследование, направленное на изучение тектонической трещиноватости в пределах одной из складок южного крыла складчатого сооружения Северо-Западного Кавказа, проведено с помощью структурно-парагенетического и катакластического методов анализа. Объектом изучения являлась Семисамская антиклиналь (рис. 1 и 2), сложенная верхнемеловыми и палеогеновыми слоистыми терригенно-карбонатными отложениями, в которых широко развиты различные геологические индикаторы палеонапряжений (рис. 3, 5, 7, 9).

В пределах изученной складчатой структуры установлен парагенез, связанный с действием субгоризонтальных минимальных сжимающих (девиаторное растяжение) напряжений северо-западной (С3 320 ) ориентировки и фиксируемый отрывно-сбросовыми системами северо-восточного простирания (рис. 6, 8, 10, 11, 17). Взбросо-надвиговые 
системы северо-западного (СЗ-ЮВ) простирания, играющие заметную роль во всем складчатом сооружении СевероЗападного Кавказа, представлены в основном на крыльях Семисамской антиклинали (рис. 6, 12, 13)

Распределение рассчитанных с помощью метода катакластического анализа локальных характеристик поля палеонапряжений (локальные стресс-состояния) показывает существенные вариации единого поля напряжений, действующего при формировании складчатого сооружения (рис. 15-17).

В пределах антиклинальной складки установлена значительная вариация обстановок, обусловленных изменением пространственного положения главных осей напряжения (рис. 18). Области с горизонтальным растяжением в осевой части складки закономерно сменяются областями горизонтального сжатия на ее крыльях (рис. 19).

Ключевые слова: палеонапряжения, локальные стресс-состояния, тектонический режим, складка, антиклиналь, отрыв, сброс, взброс, надвиг, зеркало скольжения.

\section{1. ВВЕДЕНИЕ}

Изучение тектонической трещиноватости с использованием структурно-парагенетического метода [Rastsvetaev, 1987] на северо-западном окончании Большого Кавказа начато тектодинамической группой МГУ в 1995 г. Были проведены исследования на северозападном погружении Новороссийского синклинория в районе городов Анапа и Новороссийск, а также вблизи Псебепской антиклинальной зоны около ст. Варениковской. Согласно результатам проведенных исследований, здесь выявлены структурные парагенезы, связанные с тремя основными субгоризонтальными направлениями действия максимальных сжимающих напряжений: северо-восточным, субмеридиональным и северо-западным [Rastsvetaev et al., 1999; Marinin, 2003; Marinin, Rastsvetaev, 2008]. Северо-восточное сжатие обусловливало развитие структурных парагенезов, формировавшихся в процессе складкообразования и согласующихся с простиранием крупных складчатых структур Новороссийского синклинория (сжатие ортогонально ориентировано к этим структурам). По данным этих исследований, субмеридиональная ориентировка максимальных сжимающих напряжений в изученном районе проявлена очень слабо и имеет в основном региональное значение. Северо-западная (до СС3) ориентировка максимальных сжимающих напряжений в подавляющем числе случаев проявлена хронологически позднее, нежели северо-восточная, причем в миоценовых отложениях она зачастую единственно хорошо проявленная [Marinin, 2003; Marinin, Saintot, 2012]. Помимо подробных полевых исследований тектодинамической группы МГУ, в той или иной мере рассматриваемый район охватывают региональные работы Л.М. Расцветаева [Rastsvetaev, 1977], В.А. Вигинского [Viginsky, 1986], П.Н. Николаева [Nikolaev, 1992] и Ю.Г. Леонова с соавторами [Leonov et $a l ., 2001]$. Кроме того, несколько определений локальных стресс-состояний выполнены в рассматриваемом районе французскими исследователями [Saintot, Angelier, 2002].

Указанные выше исследования выявили основные черты тектодинамического строения района, но вместе с тем остался не до конца выясненным характер распределения направлений главных напряжений, как в плане, так и по относительной хронологической последовательности. Особый интерес вызывает предполагаемая зависимость распределения локальных стресс-тензоров от их местоположения в пределах крупных складчатых и дизъюнктивных структур.

C целью определения характера распределения главных напряжений в пределах крупной складчатой структуры и выявления относительной хронологической последовательности действующих здесь стрессрежимов коллективом тектонофизического отряда ИФЗ РАН в 2011-2012 гг. проведены полевые работы на северо-западном окончании складчатой системы Большого Кавказа. Основными объектами исследований являлись структурные парагенезы тектонической трещиноватости и малых структурных форм на крыльях Семисамской антиклинали, расположенной на южном крыле Новороссийского синклинория и протягивающейся через весь полуостров Абрау в западносеверо-западном направлении. Ядерная часть этой складки сложена породами верхнего кампана - маастрихта, на крыльях обнажаются маастрихт-датские образования (рис. 1). Ширина складки 6-8 км (по подошве датских отложений), а протяженность более 30 км. Антиклиналь характеризуется в целом довольно спокойными относительно пологими залеганиями на крыльях от 15 до $25^{\circ}$. Лишь в приосевой ее части нами были встречены крутые или даже опрокинутые залегания (в юго-восточной части вблизи оз. Абрау). Формирование основных разрывно-складчатых структур Северо-Западного Кавказа оценивается различными авторами в достаточно широком возрастном диапазоне (поздний маастрихт - плиоцен). Согласно наиболее распространенному мнению [Shcheglov, Chekunov, 1991; Nesmeyanov, 1992; Afanasenkov et al., 2007], время формирования складчатой структуры Семисамской антиклинали и связанных с ней парагенезов можно отнести к позднему эоцену - олигоцену. На уже сформированной складчатой структуре антиклинали с резким угловым несогласием залегают отложения плиоцена.

В процессе полевых исследований нами собрана 


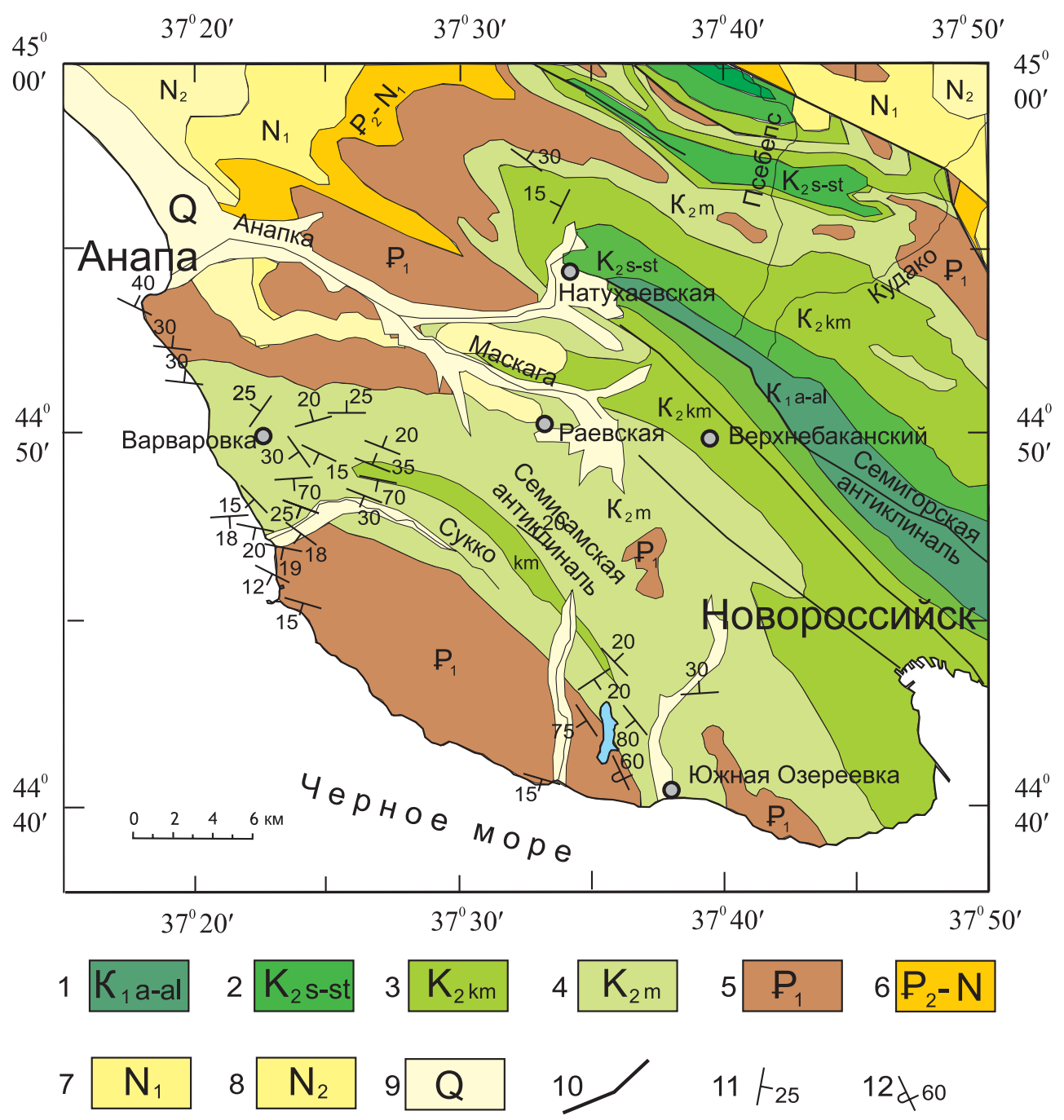

Рис. 1. Геологическая схема района Семисамской антиклинали (составлена по материалам В.А. Сереженко и В.И. Резникова).

1-9 - области распространения отложений: 1 - апта - альба, 2 - сеномана - сантона, 3 - кампана, 4 - маастрихта, 5 - палеоцена, 6 - эоцена - майкопа, 7 - миоцена, 8 - плиоцена, 9 - антропогена; 10 - разрывные нарушения; 11-12 - элементы залегания слоистости (по данным автора): 11 - нормальные, 12 - опрокинутые.

Fig. 1. The geological scheme of the Semisamskaya anticline area (based on data provided by V.A. Serezhenko and V.I. Reznikov). 1-9 - sedimentation areas: 1 - Aptian-Albian, 2 - Cenomanian-Santonian, 3 - Campanian, 4 - Maastrichtian, 5 - Paleocene, 6 - Eocene - Maikop, 7 - Miocene, 8 - Pliocene, 9 - Anthropogene; 10 - faults; 11-12 - elements of bedding stratification (according to the author's data): 11 normal, 12 - overthrusted.

информация по распределению тектонической трещиноватости и малым структурным формам в 52 точках наблюдения в разных частях складки (рис. 2). Наиболее подробно рассмотрено строение складки в прибрежной части, благодаря практически стопроцентной обнаженности отложений в береговом клифе.

\section{2. МЕТОДЫ ИССЛЕДОВАНИЯ}

Для изучения особенностей распределения геологических индикаторов палеонапряжений разного типа и масштаба использовался метод структурно-параге- нетического анализа [Rastsvetaev, 1987]. В методе задействованы три группы геологических индикаторов: 1) дизъюнктивы раздвижения (трещины отрыва, раздвиги, жилы, дайки); 2) дизъюнктивы содвижения (плоскости рассланцевания и кливажа, стилолитовые швы); 3) дизъюнктивы сдвига в «механическом» смысле этого слова (трещины скола, сдвиги, сбросы, взбросы, надвиги, шарьяжи). Индикаторы первой группы позволяют довольно уверенно определять положение оси максимального девиаторного растяжения и менее уверенно - оси максимального сжатия. Дизъюнктивы второй группы, напротив, более точно указывают положение оси максимального сжатия. Суть 


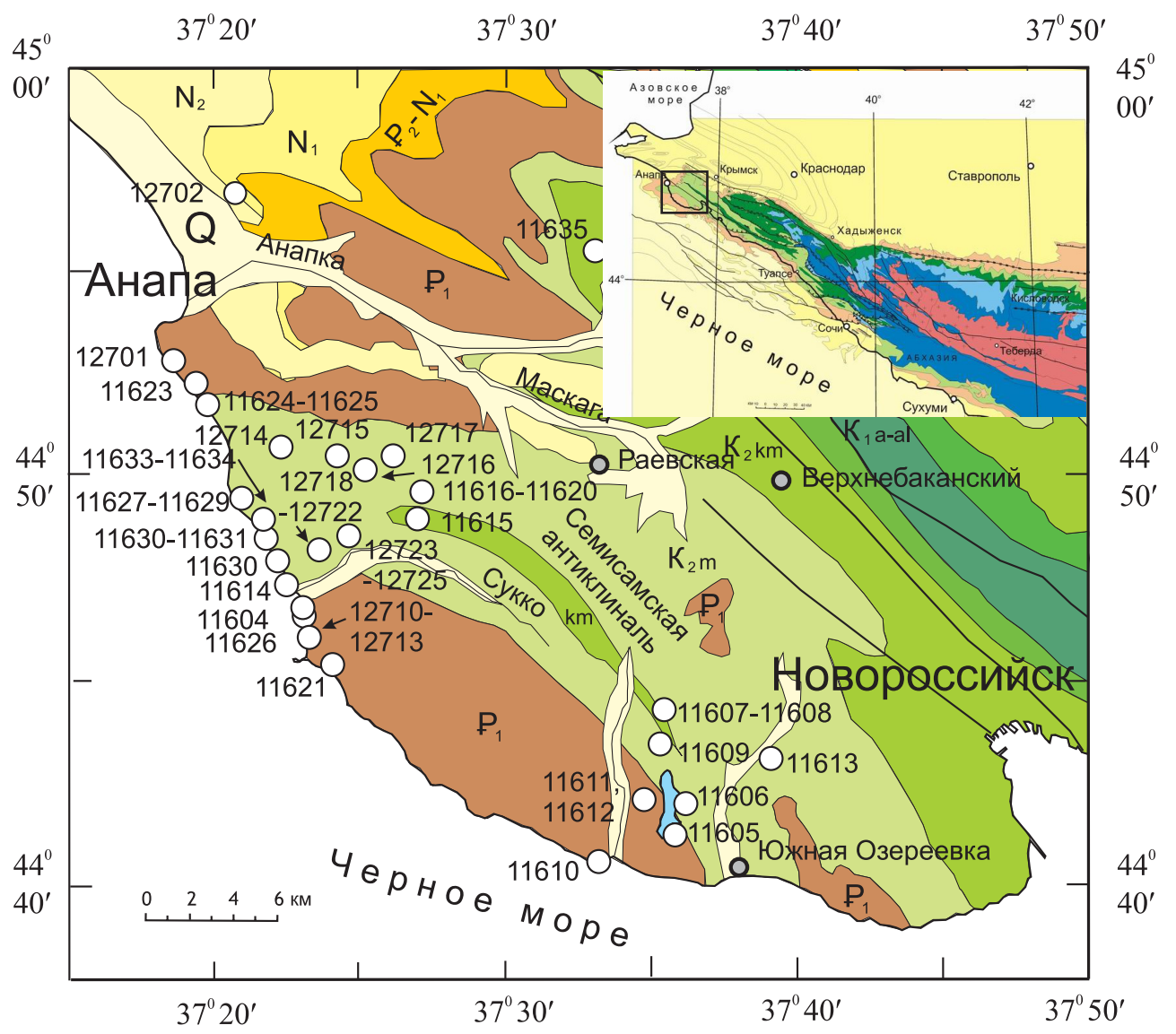

Рис. 2. Схема месторасположения точек наблюдения (на врезке показана обзорная геологическая карта складчатого сооружения Северо-Западного Кавказа и положение на ней изученного района).

Fig. 2. The scheme showing locations of observation sites (the insert shows a general geological map of the folded structure of the North-Western Caucasus and the position of the area under study).

парагенетического метода заключается в выявлении характерных парагенезов разрывных структур, соответствующих определенному типу напряженно-деформированного состояния, при этом условием корректности получаемых результатов является геологическая одновозрастность задействованных индикаторов и их принадлежность к структурным ансамблям одного ранга.

Для обработки полученных замеров по трещинам с установленным характером смещений использовался метод катакластического анализа [Rebetsky, 2007], с помощью которого возможно определить количественные характеристики локальных стресс-состояний: положение осей главных напряжений и коэффициент Лоде-Надаи. В зависимости от близости положения осей главных напряжений к оси на зенит (то есть от их пространственной ориентировки) определяются обстановки горизонтального растяжения, горизонтального сдвига и горизонтального сжатия, а также их различные сочетания. В применении к реконструкции тектонических напряжений для участков земной коры по сейсмологическим данным эти обстановки характеризуют геодинамический тип напряженного состояния.
Зарубежные исследователи [Chang et al., 2003; Saintot, Angelier, 2002] для обозначения полученных с помощью полевых измерений основных типов пространственной ориентации главных осей напряжения используют в своих публикациях термины «тектонический режим» или «стресс-режим» (tectonic regime, stress regime). Реконструкция по геологическим данным базируется на тех же теоретических положениях метода катакластического анализа, что и алгоритм реконструкции современных напряжений по сейсмологическим данным о механизмах очагов землетрясений. Однако имеется ряд различий, обусловленных характером исходных данных. Во-первых, геологические данные позволяют определить пространственную ориентацию плоскости трещины и направление относительного перемещения ее бортов. Другое отличие состоит в отсутствии у геологических индикаторов точной привязки по времени для каждого события. Не всегда удается установить и относительную хронологическую последовательность или приуроченность к определенным структурным парагенезам. Довольно часты случаи, когда на одной площадке сбора данных (в одном обнажении) встречаются плоскости зеркал скольжения 

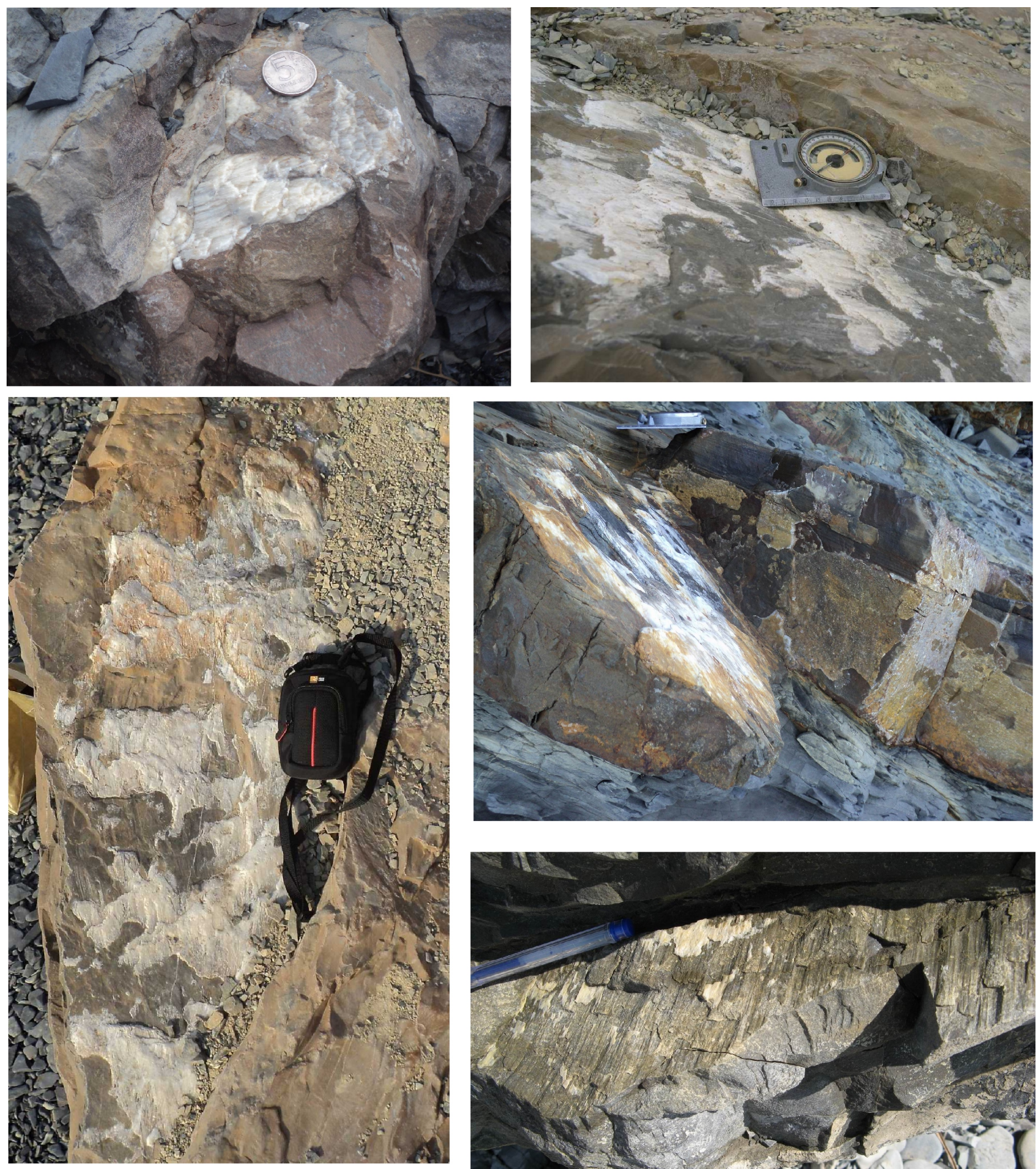

Рис. 3. Примеры зеркал скольжения, наблюдаемых в пределах Семисамской антиклинали в верхнемеловых (маастрихтских) и палеогеновых (датских) отложениях (точки наблюдения 11621, 11604, 11624, 11626 и 11625).

Fig. 3. Examples of slickensides observed within the limits of the Semisamskaya anticline in the Upper Cretaceous (Maastrichtian) and Paleocene (Danish) sediments (observation sites 11621, 11604, 11624, 11626, and 11625). 
A.V. Marinin: The tectonophysical researches of the Semisamskaya anticline...

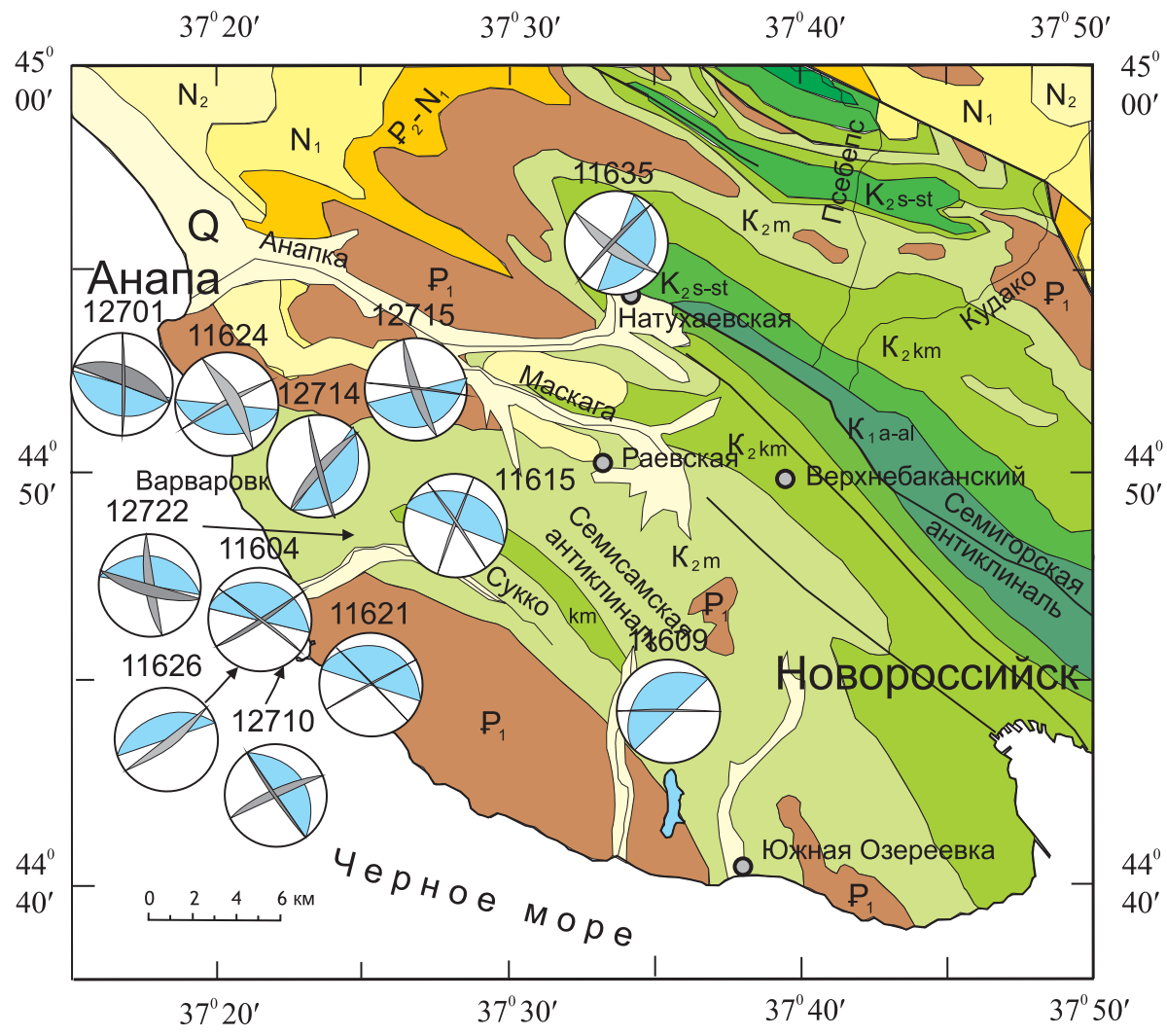

Рис. 4. Системы «первичной» трещиноватости Семисамской антиклинали и элементы залегания слоистости на круговых диаграммах (стереографическая проекция на верхнюю полусферу).

Проекции плоскостей систем трещиноватости показаны серым, а проекции элементов залегания слоистости голубым цветом.

Fig. 4. 'Primary' fracturing systems in the Semisamskaya anticline, and bedding elements in circle diagrams (stereographic projections to the upper hemisphere).

Projections of planes of the fracturing systems are shown in grey, and projections of bedding dip are shown in blue.

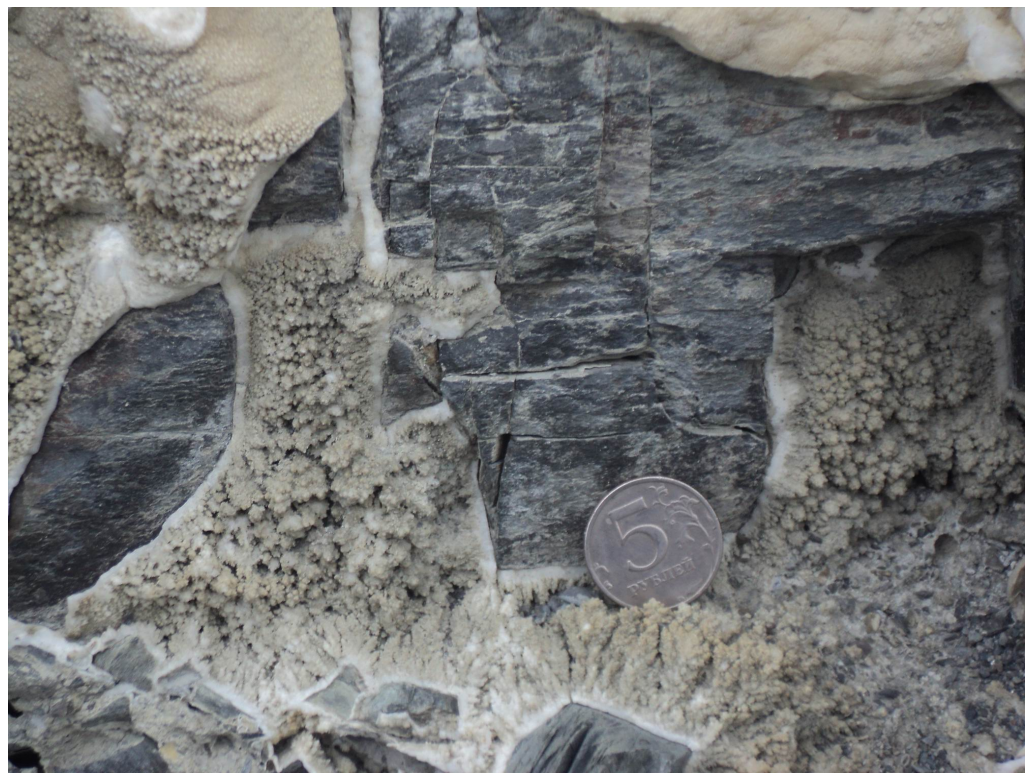

Рис. 5. «Молодые» отрывы северо-западного простирания в породах датского яруса на юго-западном крыле Семисамской антиклинали, т.н. 11621.

Fig. 5. 'Young' joints of the north-western strike in the Danish rocks in the south-western wing of the Semisamskaya anticline, observation site 11621 

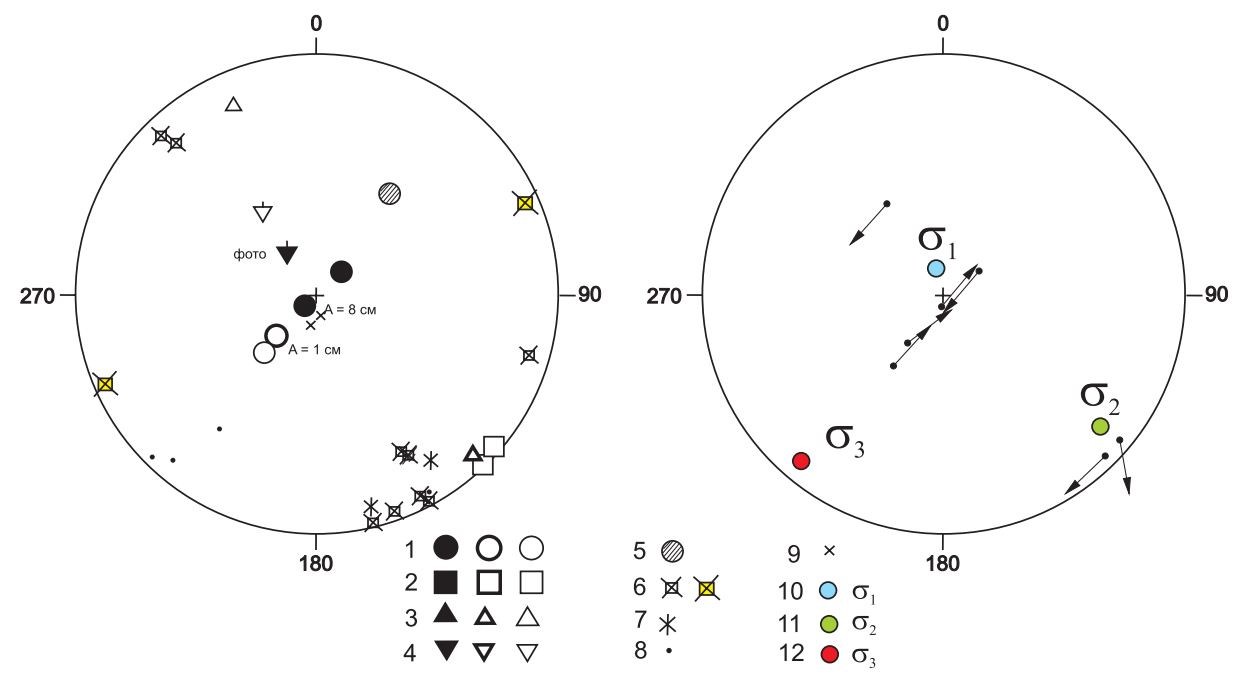

Рис. 6. Круговые диаграммы (стереографическая проекция на верхнюю полусферу), показывающие полюсы плоскостей тектонических трещин разного типа (слева) и положение осей главных напряжений, определенных методом катакластического анализа (справа) в т.н. 11621 (юго-западное крыло Семисамской антиклинали, к востоку от пос. Большой Утриш).

1-8 - полюсы тектонических трещин с преимущественным типом перемещений: 1 - взбросы, 2 - сбросы, 3 - правые сдвиги, 4 - левые сдвиги, 5 - разрывы взбросового типа, 6 - отрывы (с желтой заливкой более поздние), 7 - жилы, 8 - трещины (сколового типа); 9 - элементы залегания слоистости (нормальное); 10-12 - ориентировка осей главных нормальных напряжений: 10 - минимальных (растяжение), 11 - промежуточных, 12 - максимальных (сжатие). Заливка значков (1-4) указывает на степень достоверности определения кинематики смещения: сплошная заливка - отличная (с амплитудой), заливка по краям - хорошая, без заливки - предполагаемая. Стрелками на правой диаграмме показано направление перемещения висячего блока в полюсах трещин, которые были использованы при реконструкции палеонапряжений по методу катакластического анализа.

Fig. 6. Circle diagrams (stereographic projections to the upper hemisphere) showing poles of planes of different tectonic fractures (left) and positions of principal stress axes determined by cataclastic analysis (right) on observation site 11621 (the south-western wing of the Semisamskaya anticline which is located east of Bolshoi Utrish settlement).

1-8 - poles of tectonic fractures and dominant displacement types: 1 - reverse faults, 2 - normal faults, 3 - right-sided strike-slip faults, 4 - leftsided strike-slip faults, 5 - fractures of reverse type, 6 - detachments (older ones are coloured in yellow), 7 - veins, 8 - shears; 9 - (normal) bedding elements; 10-12 - orientations of principal normal stress axes: 10 - minimal (extension), 11 - intermediate, 12 - maximal (compression). Coloured labels (1-4) indicate degrees of reliability of displacement kinematics determinations: solid colour - perfect (including amplitudes), coloured margins - good, no colour - assumed. Arrows in the right diagram show displacement directions of hanging walls at fracture poles which are referred to in paleostress reconstructions by cataclastic analysis.

с несколькими направлениями штриховок (борозд скольжения), характеризующими в разных случаях либо близкие по времени события, укладывающиеся в единый этап деформирования, либо хронологически разные фазы эволюции напряженного состояния. В используемой нами для расчетов компьютерной программе STRESSgeol принцип разделения сколов на однородные выборки, определяющие временные фазы квазиоднородного деформирования макрообъема, подчинен достижению максимальности суммарной энергии диссипации при минимальном количестве выделяемых фаз.

\section{3. РЕЗУЛЬТАТЫ ПОЛЕВЫХ ИССЛЕДОВАНИЙ}

Полученные в процессе полевых исследований данные по трещинам с установленным типом смещений (прежде всего это зеркала скольжения) характеризовались достаточно четким определением кине- матики. Общее количество собранных замеров тектонической трещиноватости - более 550, из них со структурно-кинематической информацией (с определением направления перемещения на поверхности трещины) - 190 замеров, а по отрывным структурам собрано более 130 замеров. Существенная часть собранных замеров охарактеризована измеренной реальной амплитудой и направлением смещения, что возможно благодаря ритмичному чередованию слоев разной мощности и литологии, которые четко идентифицируются на разных крыльях дизъюнктивного нарушения. Большая часть замеров проведена по зеркалам скольжения, выполненным минеральным заполнителем (в основном кальцитом) с образованием четких ступеней (рис. 3). Все полученные замеры охарактеризованы отчетливыми бороздами скольжения, определяющими направление относительного перемещения крыльев тектонических трещин и малых разрывных нарушений, что повышает ценность полученных полевых тектонофизических данных для изучения природ- 


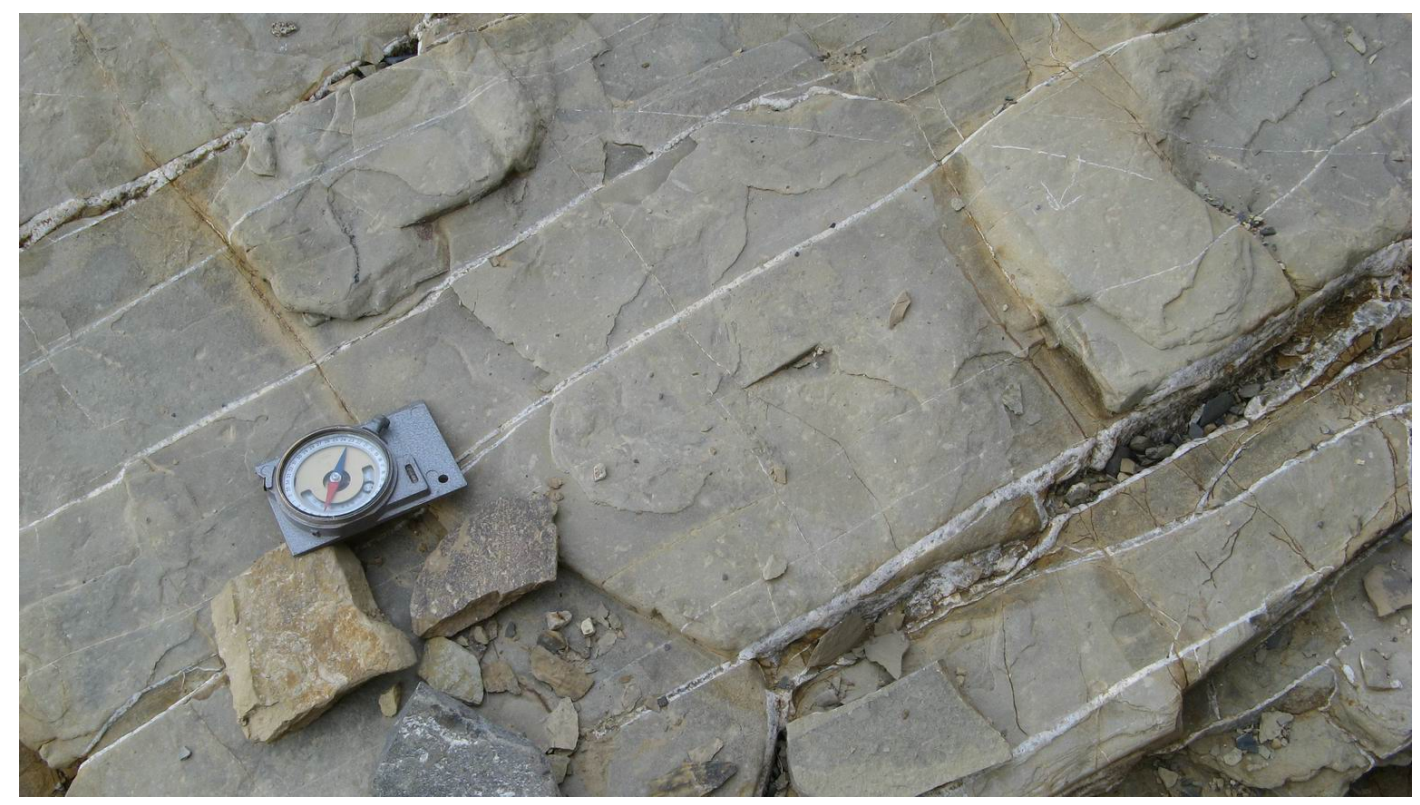

Рис. 7. Система отрывов северо-восточного простирания в породах маастрихтского яруса на юго-западном крыле Семисамской антиклинали, т.н. 11604.

Fig. 7. The system of joints of the north-eastern strike in the Maastrichtian rocks in the south-western wing of the Semisamskaya anticline, observation site 11604.

ных палеонапряжений в молодых складчатых системax.

С помощью структурно-парагенетического метода [Rastsvetaev, 1987] проведен анализ кинематических типов геологических стресс-индикаторов палеонапряжений в пределах Семисамской антиклинали. Сложенная преимущественно карбонатно-терригенными породами Семисамская антиклиналь характеризуется широким развитием «первичной» или основной (master-crack) тектонической трещиноватости (так называемой тектонической «делимости»). В большинстве случаев помимо трещиноватости, субпараллельной поверхностям напластования (слоистости), хорошо проявлены еще 1-2 системы трещиноватости. Обращает на себя внимание преимущественно субвертикальное положение систем «основной» трещиноватости с углами падения от 75 до $90^{\circ}$ (рис. 4). Простирание систем трещиноватости плавно изменяется при переходе с одной части антиклинали на другую. На южном крыле Семисамской антиклинали системы имеют северо-западное и северо-восточное, а в приосевой части - северо-северо-западное и северо-северо-восточное простирание. На северном крыле сконцентрированы системы с субмеридиональным и восточно-северо-восточным простиранием. Углы между системами в большинстве случаев составляют от 75-90 на крыльях складки до 55-65 в приосевой ее части. Плотность систем варьируется в широких пределах - от 1-2 до 60-70 трещин на погонный метр (обычно 3-6 трещин на погонный метр).
Наиболее закономерным распределением отличаются отрывные и сбросовые разрывные системы. На обоих крыльях Семисамской антиклинали и в ее приосевой части зафиксированы крупные максимумы сбросов - 320 $\angle 70-80^{\circ}$ и отрывов - 320 $\angle 80^{\circ}$. На югозападном крыле антиклинали в районе пос. Большой Утриш проявлены отрывные и сбросовые структуры северо-восточного простирания (рис. 6). Кроме того, здесь проявлено более «молодое» северо-восточное $\left(\mathrm{CB} 70^{\circ}-\mathrm{F}^{250^{\circ}}\right.$ ) девиаторное растяжение. Отрывы, связанные с этим растяжением, нарушают все другие сколовые и отрывные структуры (рис. 5 и 6).

Северо-западнее в т.н. 11604 вблизи долины р. Сукко система отрывов и сбросов северо-восточного (до $\mathrm{BCB}$ ) простирания проявлена особенно четко (рис. 7). Значительно слабее проявлены системы отрывов северо-северо-восточного и западно-северо-западного простирания (рис. 8). Во всех наблюдаемых системах помимо кальцитовой минерализации отмечается интенсивное ожелезнение. По результатам расчета методом катакластического анализа установлены следующие ориентировки осей главных напряжений: $\sigma_{1}-138 \angle 6^{\circ}$, $\sigma_{2}-231 \angle 30^{\circ}, \sigma_{3}-39 \angle 60^{\circ}$. Здесь определяются условия горизонтального растяжения с субвертикальным положением оси $\sigma_{3}$, а также горизонтальным положением осей $\sigma_{1}$ и $\sigma_{2}$ при коэффициенте Лоде-Надаи $\mu_{\sigma}=-0.28$.

К северо-западу от устья р. Сукко (ближе к осевой части Семисамской антиклинали) в т.н. 11614 и в т.н. 11633 зафиксированы системы сбросов и взрезов 

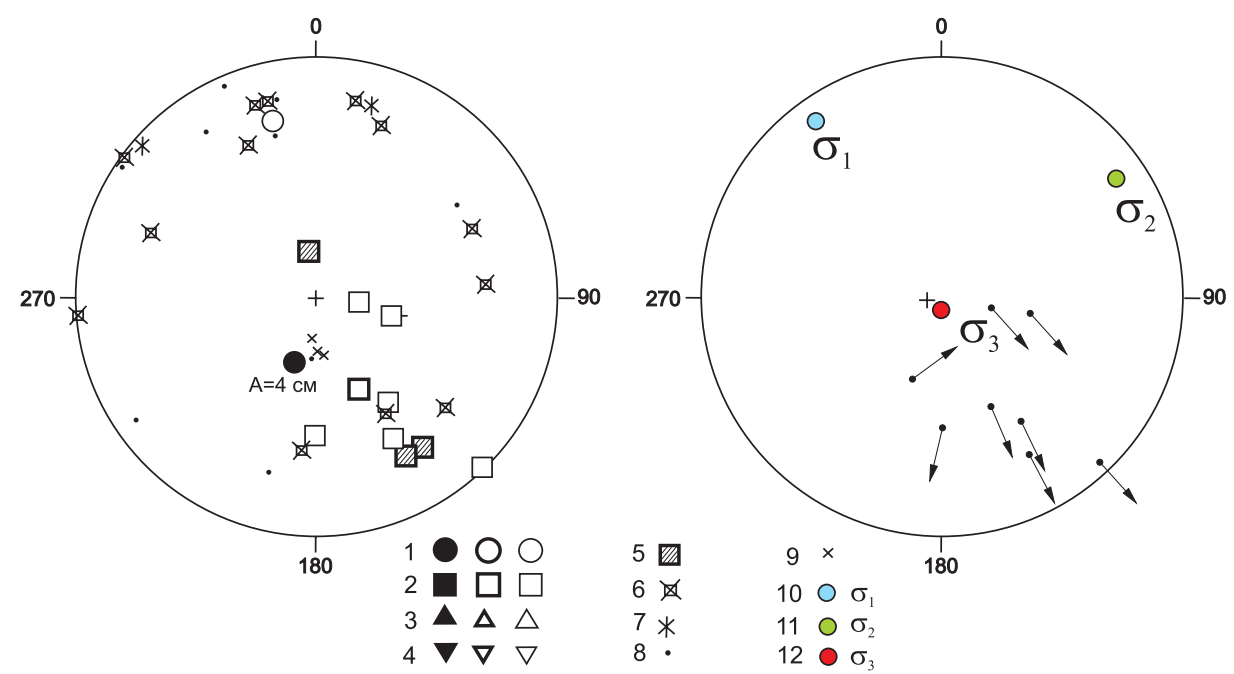

Рис. 8. Круговые диаграммы (стереографическая проекция на верхнюю полусферу), показывающие полюсы плоскостей тектонических трещин разного типа (слева) и положение осей главных напряжений, определенных методом катакластического анализа (справа) в т.н. 11604 (юго-западное крыло Семисамской антиклинали).

1-8 - полюсы тектонических трещин с преимущественным типом перемещений: 1 - взбросы, 2 - сбросы, 3 - правые сдвиги, 4 - левые сдвиги, 5 - разрывы сбросового типа, 6 - отрывы, 7 - жилы, 8 - трещины (сколового типа); 9 - элементы залегания слоистости (нормальное); 10-12 - ориентировка осей главных нормальных напряжений: 10 - минимальных (растяжение), 11 - промежуточных, 12 максимальных (сжатие). Заливка значков (1-4) указывает на степень достоверности определения кинематики смещения: сплошная заливка - отличная (с амплитудой), заливка по краям - хорошая, без заливки - предполагаемая. Стрелками на правой диаграмме показано направление перемещения висячего блока в полюсах трещин, которые были использованы при реконструкции палеонапряжений по методу катакластического анализа.

Fig. 8. Circle diagrams (stereographic projections to the upper hemisphere) showing poles of planes of different tectonic fractures (left) and positions of principal stress axes determined by cataclastic analysis (right) on observation site 11604 (the south-western wing of the Semisamskaya anticline).

1-8 - poles of tectonic fractures and dominant displacement types: 1 - reverse faults, 2 - normal faults, 3 - right-sided strike-slip faults, 4 - leftsided strike-slip faults, 5 - fractures of normal-fault type, 6 - detachments, 7 - veins, 8 - shears; 9 - (normal) bedding elements; 10-12orientations of principal normal stress axes: 10 - minimal (extension), 11 - intermediate, 12 - maximal (compression). Coloured labels (1-4) indicate degrees of reliability of displacement kinematics determinations: solid colour - perfect (including amplitudes), coloured margins - good, no colour - assumed. Arrows in the right diagram show displacement directions of hanging walls at fracture poles which are referred to in paleostress reconstructions by cataclastic analysis.

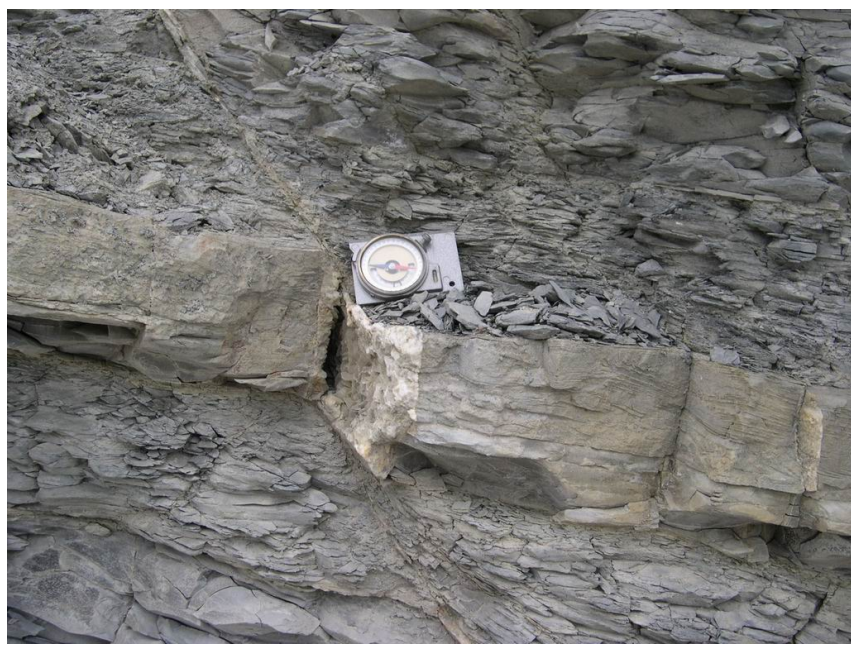

Рис. 9. Сбросово-отрывный парагенез в маастрихтских отложениях на юго-западном крыле Семисамской антиклинали (т.н. 11633).

В верхней части фотографии зеркало скольжения (Аз. пад. $180 \angle 35^{\circ}$ ) со сбросовой штриховкой и видимой амплитудой смещения 20 см (по сместителю), в центральной - отрыв (Аз. пад. $150 \angle 80^{\circ}$ ) с кальцитовыми «щётками» по 2 см и зиянием 2 см, в нижней части - зеркало скольжения (Аз. пад. $145 \angle 30^{\circ}$ ) со сбросовой штриховкой и амплитудой смещения 3 см.

Fig. 9. Normal faulting-jointing paragenesis in the Maastrichtian sediments in the south-western wing of the Semisamskaya anticline (observation site 11633).

At the top of the photo - a slickenside (dip azimuth $180 \angle 35^{\circ}$ ) with normal faulting striations and a visible displacement amplitude of $20 \mathrm{~cm}$ (alongside); in the centre - a joint (dip azimuth $150 \angle 80^{\circ}$ ) with $2 \mathrm{~cm}$ calcite 'brushes' with $2 \mathrm{~cm}$ gaps; at the bottom - a slickenside (dip azimuth $145 \angle 30^{\circ}$ ) with normal faulting striations and a displacement amplitude of $3 \mathrm{~cm}$. 

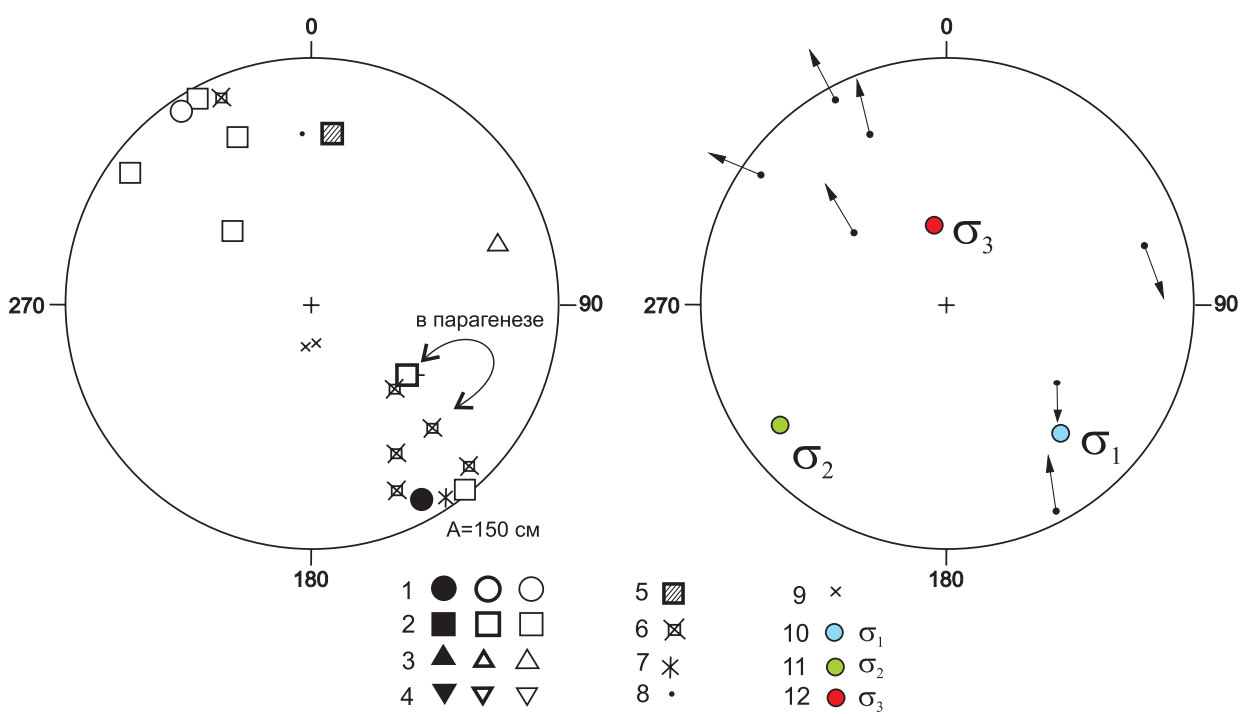

Рис. 10. Круговые диаграммы (стереографическая проекция на верхнюю полусферу), показывающие полюсы плоскостей тектонических трещин разного типа (слева) и положение осей главных напряжений, определенных методом катакластического анализа (справа) в т.н. 11614 (юго-западное крыло Семисамской антиклинали).

1-8 - полюсы тектонических трещин с преимущественным типом перемещений: 1 - взбросы, 2 - сбросы, 3 - правые сдвиги, 4 - левые сдвиги, 5 - разрывы сбросового типа, 6 - отрывы, 7 - жилы, 8 - трещины (сколового типа); 9 - элементы залегания слоистости (нормальное); 10-12 - ориентировка осей главных нормальных напряжений: 10 - минимальных (растяжение), 11 - промежуточных, 12 максимальных (сжатие). Заливка значков (1-4) указывает на степень достоверности определения кинематики смещения: сплошная заливка - отличная (с амплитудой), заливка по краям - хорошая, без заливки - предполагаемая. Стрелками на правой диаграмме показано направление перемещения висячего блока в полюсах трещин, которые были использованы при реконструкции палеонапряжений по методу катакластического анализа.

Fig. 10. Circle diagrams (stereographic projections to the upper hemisphere) showing poles of planes of different tectonic fractures (left) and positions of principal stress axes determined by cataclastic analysis (right) on observation site 11614 (the south-western wing of the Semisamskaya anticline).

1-8 - poles of tectonic fractures and dominant displacement types: 1 - reverse faults, 2 - normal faults, 3 - right-sided strike-slip faults, 4 - leftsided strike-slip faults, 5 - fractures of normal-fault type, 6 - detachments, 7 - veins, 8 - shears; 9 - (normal) bedding elements; $10-12$ - orientations of principal normal stress axes: 10 - minimal (extension), 11 - intermediate, 12 - maximal (compression). Coloured labels (1-4) indicate degrees of reliability of displacement kinematics determinations: solid colour - perfect (including amplitudes), coloured margins - good, no colour assumed. Arrows in the right diagram show displacement directions of hanging walls at fracture poles which are referred to in paleostress reconstructions by cataclastic analysis.

(взбросов) восточно-северо-восточного простирания и парагенетически связанных с ними отрывов, что устанавливается непосредственными полевыми наблюдениями и общим минеральным выполнением (рис. 9). При помощи метода катакластического анализа по структурно-кинематическим данным о трещинах рассчитаны следующие ориентировки осей главных напряжений: $\sigma_{1}-318 \angle 6^{\circ}, \sigma_{2}-51 \angle 25^{\circ}, \sigma_{3}-217 \angle 64^{\circ}$. При этом область выходов максимума полюсов отрывов четко совпадает с положением реконструированной нами оси растяжения $\left(\sigma_{1}\right)$. В точке устанавливается единый этап деформирования, при котором все измеренные индикаторы палеонапряжений укладываются в единственное решение по методу катакластического анализа и образуют единый структурный парагенез (рис. 10).

В районе пансионата Шингари (т.н. 11627-11629) в береговом клифе хорошо видно строение приосевой части Семисамской антиклинали (рис. 11). Здесь также проявлен структурный парагенез сбросов восточносеверо-восточного простирания и отрывов северо-восточного простирания. Рассчитаны следующие ориентировки осей главных напряжений: $\sigma_{1}-348 \angle 0^{\circ}, \sigma_{2}-$ $78 \angle 0^{\circ}, \sigma_{3}-270 \angle 89^{\circ}$. Положение осей определяет условия горизонтального растяжения (субвертикальное положение оси $\sigma_{3}$, горизонтальное положение осей $\sigma_{1}$ и $\left.\sigma_{2}\right)$ при коэффициенте Лоде-Надаи $\mu_{\sigma}=0.15$.

На северо-восточном крыле Семисамской антиклинали в двух близко расположенных точках наблюдения 11624 и 11625 зафиксирован сколовый парагенез субгоризонтальных правых взбросо-сдвигов и левых сдвиго-взбросов, причем если правые взбросо-сдвиги тяготеют к т.н. 11624, то большинство левых сдвиговзбросов сосредоточено в т.н. 11625. С зеркалами скольжения неразрывно связаны отрывы восточносеверо-восточного простирания (рис. 12). Севернее в т.н. 11623 проявлены сбросо-отрывные системы северо-северо-восточного простирания, что связано, 

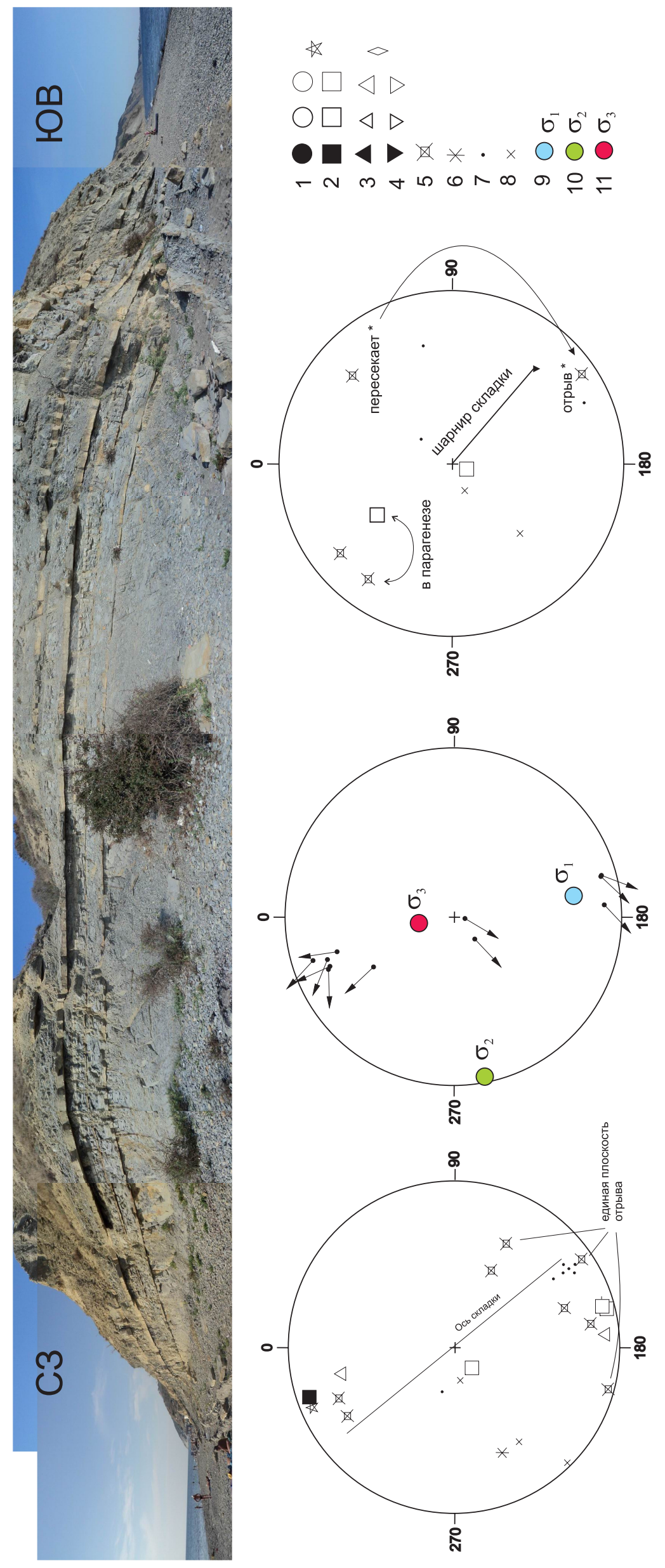

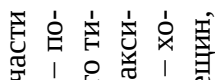

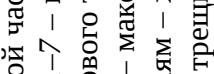

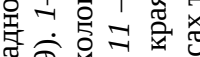

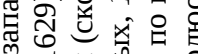

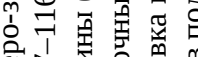

这

要

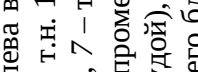

可诺

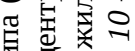

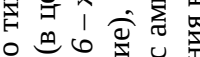

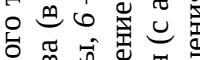

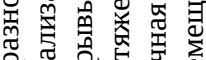

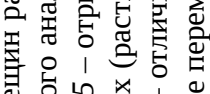

읍 늠

食

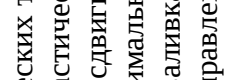

西

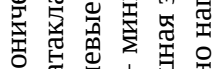

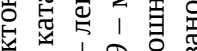

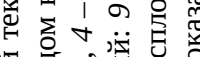

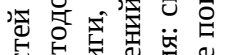

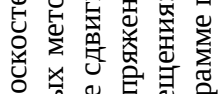

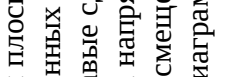

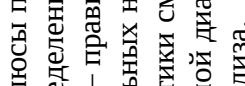

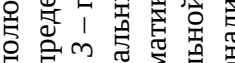

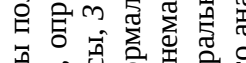

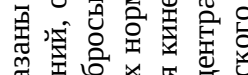

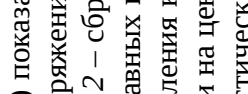

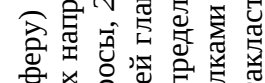

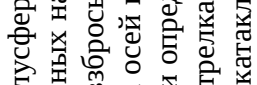

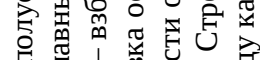

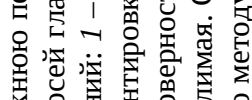

芯芯芯芯志志

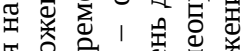

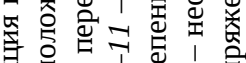

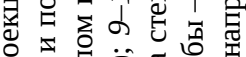

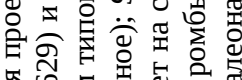

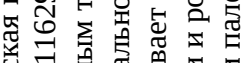

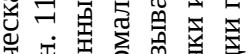

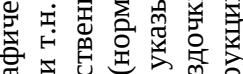

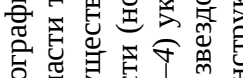

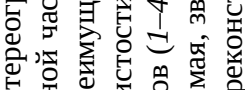

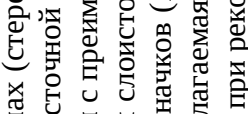

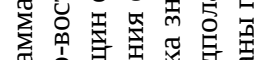

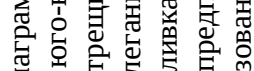

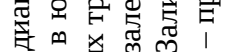

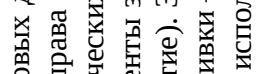

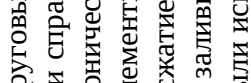

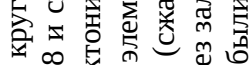

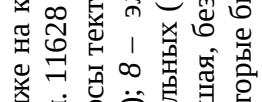

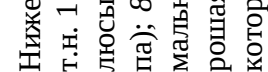

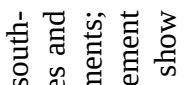

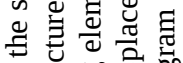

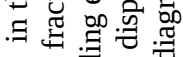

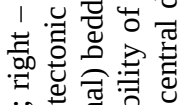

क人ष

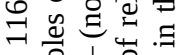

:

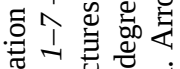

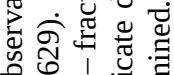

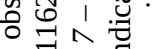

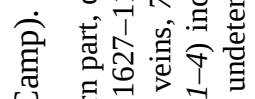

컴궈

跑

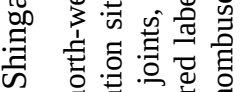

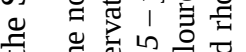

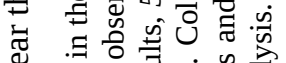

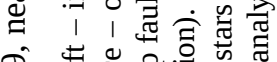

शे

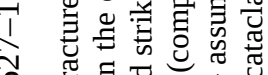

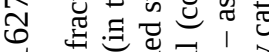

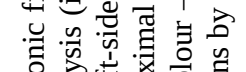

矛氙矛完

击 1 过

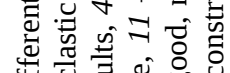

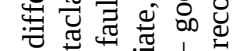

पै

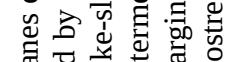

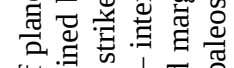

넝릴⿺

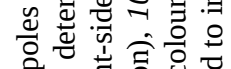

उ प

落

๑)

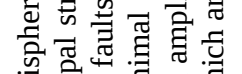

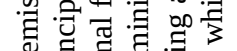

巳.

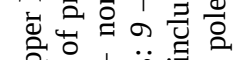

寻

I. :

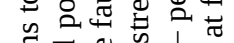

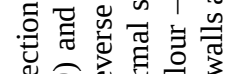

웡 8

包 1 可.

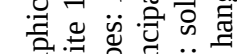

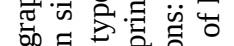

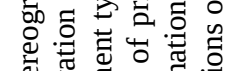

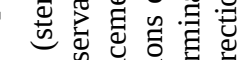

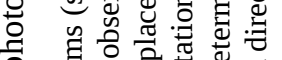

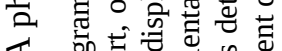

《.

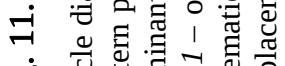

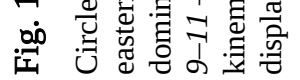



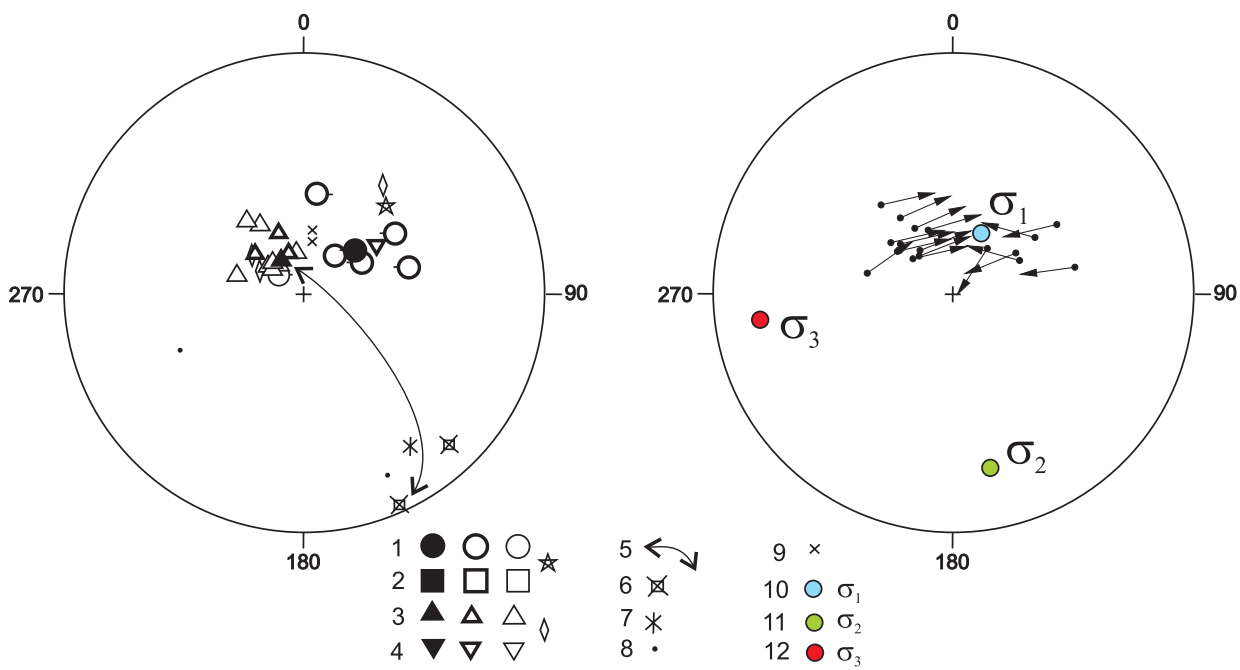

Рис. 12. Круговые диаграммы (стереографическая проекция на верхнюю полусферу), показывающие полюсы плоскостей тектонических трещин разного типа (слева) и положение осей главных напряжений, определенных методом катакластического анализа (справа) в т.н. 11624 и 11625 (северо-восточное крыло Семисамской антиклинали).

1-8 - полюсы тектонических трещин с преимущественным типом перемещений: 1 - взбросы, 2 - сбросы, 3 - правые сдвиги, 4 - левые сдвиги, 5 - единые структурные парагенезы, 6 - отрывы, 7 - жилы, 8 - трещины (сколового типа); 9 - элементы залегания слоистости (нормальное); 10-12 - ориентировка осей главных нормальных напряжений: 10 - минимальных (растяжение), 11 - промежуточных, 12 максимальных (сжатие). Заливка значков (1-4) указывает на степень достоверности определения кинематики смещения: сплошная заливка - отличная (с амплитудой), заливка по краям - хорошая, без заливки - предполагаемая. Стрелками на правой диаграмме показано направление перемещения висячего блока в полюсах трещин, которые были использованы при реконструкции палеонапряжений по методу катакластического анализа.

Fig. 12. Circle diagrams (stereographic projections to the upper hemisphere) showing poles of planes of different tectonic fractures (left) and positions of principal stress axes determined by cataclastic analysis (right) on observation sites 11624 and 11625 (the south-eastern wing of the Semisamskaya anticline).

1-8 - poles of tectonic fractures and dominant displacement types: 1 - reverse faults, 2 - normal faults, 3 - right-sided strike-slip faults, 4 - leftsided strike-slip faults, 5 - unified structural paragenesises, 6 - detachments, 7 - veins, 8 - shears; 9 - (normal) bedding elements; 10-12 - orientations of principal normal stress axes: 10 - minimal (extension), 11 -intermediate, 12 - maximal (compression). Coloured labels (1-4) indicate degrees of reliability of displacement kinematics determinations: solid colour - perfect (including amplitudes), coloured margins - good, no colour - assumed. Arrows in the right diagram show displacement directions of hanging walls at fracture poles which are referred to in paleostress reconstructions by cataclastic analysis.

видимо, с общим разворотом складчатых структур в сторону Черного моря.

Рассмотренные примеры показывают отчетливо проявленный структурный парагенез, связанный с действием субгоризонтальных минимальных сжимающих (девиаторное растяжение) напряжений северо-западной $\left(\mathrm{C} 3320^{\circ}\right)$ ориентировки и фиксируемый отрывносбросовыми системами северо-восточного простирания. Нами также отмечено, что рассматриваемые отрывы в случае совпадения их северо-восточного простирания с простиранием описанных выше систем «первичной» трещиноватости часто используют ее, а при несовпадении с ней образуют системы, связанные с растяжением в северо-западном направлении. В некоторых точках нами определен многоэтапный характер северо-западного растяжения, который устанавливается по разным генерациям минерального выполнения изученных в поле отрывных дизъюнктивов. Вблизи долины р. Сукко на крыле Семисамской антиклинали определено процентное отношение отрывов вместе с их минеральным выполнением к вмещающим породам по данному направлению (С3 320-330), которое составляет около 5.5 \%. Сама долина р. Сукко (в нижнем течении) выработана в хорошо выраженной линейной структуре восточно-северо-восточного простирания (ВСВ $\left.70^{\circ}\right)$, которая, по-видимому, также связана с действием северо-западного растяжения.

В существенно меньшем количестве точек наблюдения выявлено более молодое северо-восточное $\left(\mathrm{CB} 70^{\circ}\right)$ девиаторное растяжение. Хронологическое обоснование его более «молодого» возраста подтверждает то, что во всех наших точках наблюдения отрывные структуры, связанные с данным направлением растяжения, нарушают более ранние парагенезы тектонической трещиноватости как сколового, так и отрывного характера. Это растяжение ортогонально ориентировано к простиранию выделяемых здесь молодых (антропогеновых) Утришского и Западноутришского сбросов [Nesmeyanov, 1992].

Взбросо-надвиговые системы северо-запад - юго- 

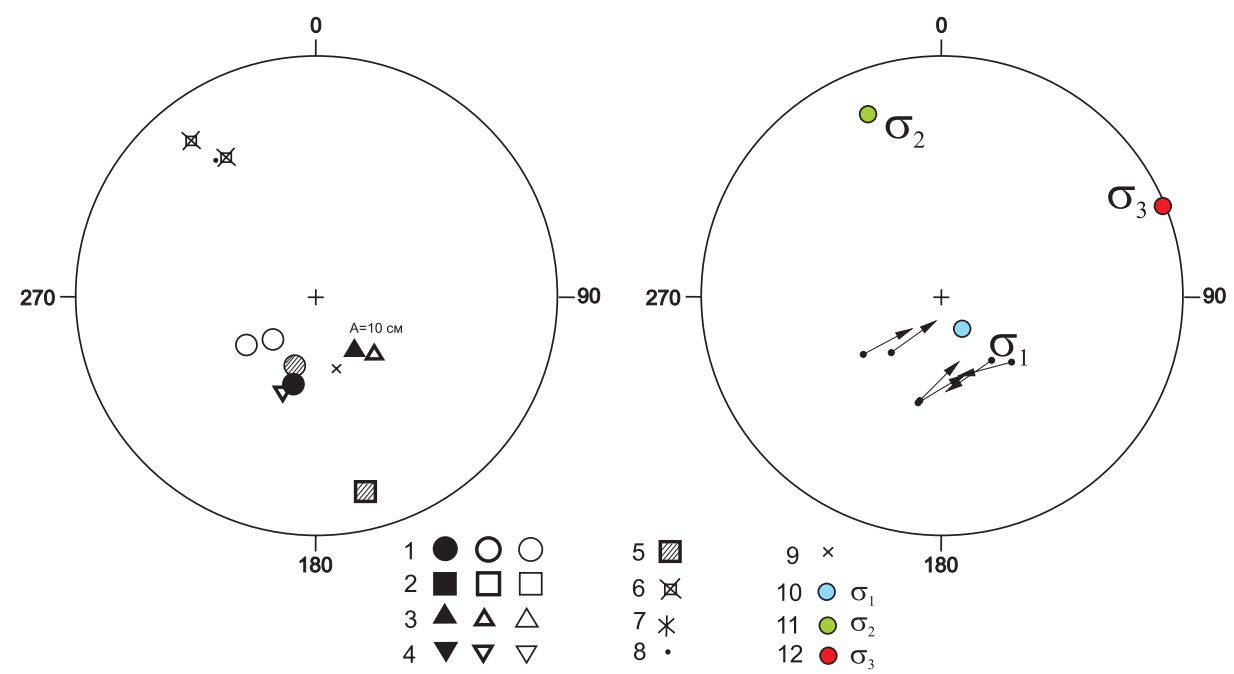

Рис. 13. Круговые диаграммы (стереографическая проекция на верхнюю полусферу), показывающие полюсы плоскостей тектонических трещин разного типа (слева) и положение осей главных напряжений, определенных методом катакластического анализа (справа) в т.н. 11626 (юго-западное крыло Семисамской антиклинали, береговой обрыв к юго-востоку от долины р. Сукко).

1-8 - полюсы тектонических трещин с преимущественным типом перемещений: 1 - взбросы, 2 - сбросы, 3 - правые сдвиги, 4 - левые сдвиги, 5 - разрывы сбросового (квадрат со штриховкой) и взбросового (круг со штриховкой) типа, 6 - отрывы, 7 - жилы, 8 - трещины (сколового типа); 9 - элементы залегания слоистости (нормальное); 10-12 - ориентировка осей главных нормальных напряжений: 10 минимальных (растяжение), 11 - промежуточных, 12 - максимальных (сжатие). Заливка значков (1-4) указывает на степень достоверности определения кинематики смещения: сплошная заливка - отличная (с амплитудой), заливка по краям - хорошая, без заливки - предполагаемая. Стрелками на правой диаграмме показано направление перемещения висячего блока в полюсах трещин, которые были использованы при реконструкции палеонапряжений по методу катакластического анализа.

Fig. 13. Circle diagrams (stereographic projections to the upper hemisphere) showing poles of planes of different tectonic fractures (left) and positions of principal stress axes determined by cataclastic analysis (right) on observation site 11626 (the south-western wing of the Semisamskaya anticline, the cliff located south-east of Sukko river basin).

1-8 - poles of tectonic fractures and dominant displacement types: 1 - reverse faults, 2 - normal faults, 3 - right-sided strike-slip faults, 4 - leftsided strike-slip faults, 5 - fractures of normal-fault type (a square with hatching) and reverse type (a circle with hatching), 6 - detachments, 7 veins, 8 - shears; 9 - (normal) bedding elements; 10-12 - orientations of principal normal stress axes: 10 - minimal (extension), 11 - intermediate, 12 - maximal (compression). Coloured labels (1-4) indicate degrees of reliability of displacement kinematics determinations: solid colour perfect (including amplitudes), coloured margins - good, no colour - assumed. Arrows in the right diagram show displacement directions of hanging walls at fracture poles which are referred to in paleostress reconstructions by cataclastic analysis.

восточного простирания, играющие заметную роль во всем складчатом сооружении Северо-Западного Кавказа, представлены только на крыльях Семисамской антиклинали. Так, на южном крыле складки с падениями на юг-юго-запад под углом около $15^{\circ}$ (Аз пд $170 \angle 15^{\circ}$, нормальное) в береговом клифе к юго-востоку от Большого Утриша (т.н. 11621) наблюдаются субгоризонтальные зеркала скольжения с надвиговыми штриховками, свидетельствующие об обстановке субгоризонтального сжатия с северо-восточной ориентировкой оси максимальных сжимающих напряжений (см. рис. 6.). При помощи метода катакластического анализа по структурно-кинематическим данным о трещинах были рассчитаны следующие ориентировки осей главных напряжений: $\sigma_{1}-135 \angle 82^{\circ}, \sigma_{2}$ - 318 $\angle 9^{\circ}, \sigma_{3}-228 \angle 0^{\circ}$. Положение осей фиксирует условия северо-восточного (СВ-Ю3) горизонтального сжатия (субгоризонтальное положение осей $\sigma_{2}$ и $\sigma_{3}$ ) при коэффициенте Лоде-Надаи $\mu_{\sigma}=-0.01$.
Ближе к долине р. Сукко в т.н. 11626 проявлены взбросо-надвиговые нарушения северо-западного простирания, связанного с действием северо-восточного субгоризонтального сжатия (рис. 13). Рассчитаны следующие ориентировки осей главных напряжений: $\sigma_{1}-$ $334 \angle 77^{\circ}, \sigma_{2}-150 \angle 13^{\circ}, \sigma_{3}-240 \angle 1^{\circ}$. Положение осей определяет условия восточно-северо-восточного горизонтального сжатия (субгоризонтальное положение осей $\sigma_{2}$ и $\sigma_{3}$ ) при коэффициенте Лоде-Надаи $\mu_{\sigma}=-0.03$.

В т.н. 11630 достаточно спокойная в целом структура Семисамской антиклинали осложнена небольшой антиклинальной складкой (с размахом крыльев около 20 м в видимой части обнажения). В отличие от окружающих участков с преобладанием горизонтального растяжения, здесь определены условия горизонтального сжатия и горизонтального сжатия в сочетании со сдвигом (рис. 14), причем при предварительных расчетах было произведено разделение собранных данных по тектонической трещиноватости для разных крыльев 

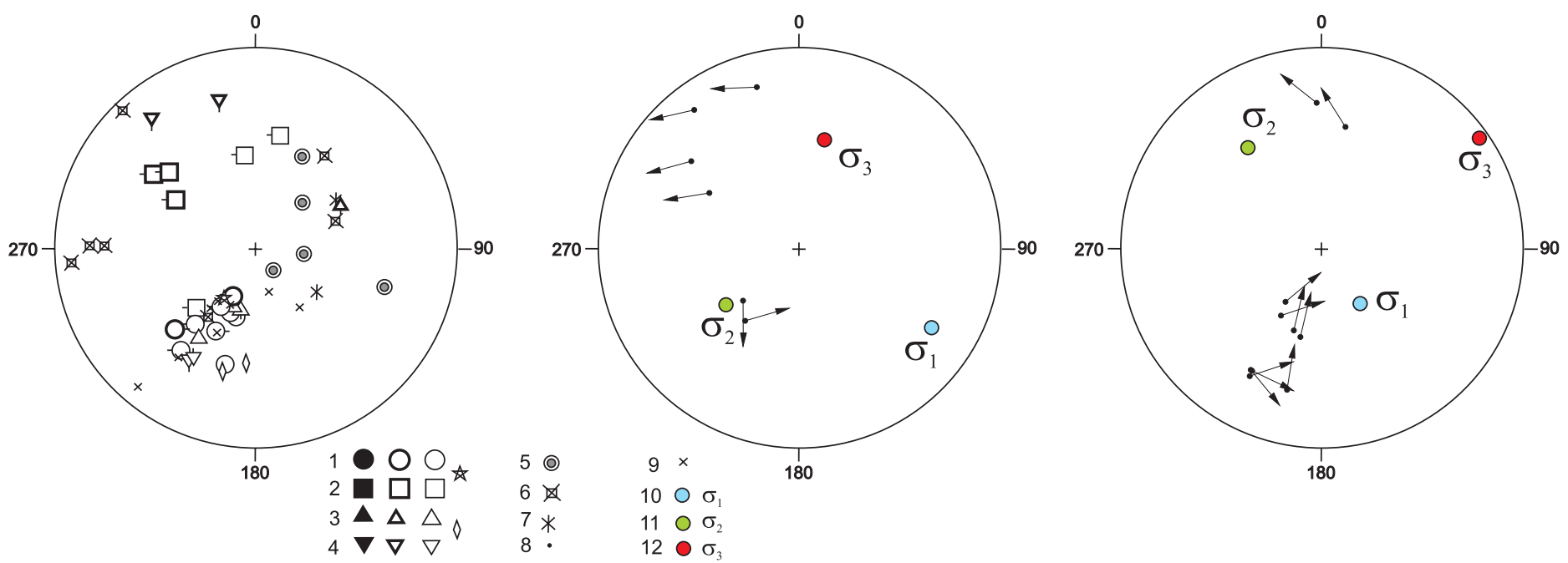

Рис. 14. Круговые диаграммы (стереографическая проекция на верхнюю полусферу), показывающие полюсы плоскостей тектонических трещин разного типа (слева) и положение осей главных напряжений, определенных методом катакластического анализа (в центре и справа) в т.н. 11630 (береговой обрыв моря к северо-западу от долины р. Сукко).

1-8 - полюсы тектонических трещин с преимущественным типом перемещений: 1 - взбросы, 2 - сбросы, 3 - правые сдвиги, 4 - левые сдвиги, 5 - разрывные зоны, 6 - отрывы, 7 - жилы, 8 - трещины (сколового типа); 9 - элементы залегания слоистости (нормальное); 10 12 - ориентировка осей главных нормальных напряжений: 10 - минимальных (растяжение), 11 - промежуточных, 12 - максимальных (сжатие). Заливка значков (1-4) указывает на степень достоверности определения кинематики смещения: сплошная заливка - отличная (с амплитудой), заливка по краям - хорошая, без заливки - предполагаемая. Стрелками на правой диаграмме показано направление перемещения висячего блока в полюсах трещин, которые были использованы при реконструкции палеонапряжений по методу катакластического анализа.

Fig. 14. Circle diagrams (stereographic projections to the upper hemisphere) showing poles of planes of different tectonic fractures (left) and positions of principal stress axes determined by cataclastic analysis (center and right) on observation site 11630 (the cliff located south-west of Sukko river basin).

1-8 - poles of tectonic fractures and dominant displacement types: 1 - reverse faults, 2 - normal faults, 3 - right-sided strike-slip faults, 4 - leftsided strike-slip faults, 5 - fault zones, 6 - joints, 7 - veins, 8 - shears; 9 - (normal) bedding elements; 10-12 - orientations of principal normal stress axes: 10 - minimal (extension), 11 - intermediate, 12 - maximal (compression). Coloured labels (1-4) indicate degrees of reliability of displacement kinematics determinations: solid colour - perfect (including amplitudes), coloured margins - good, no colour - assumed. Arrows in the right diagram show displacement directions of hanging walls at fracture poles which are referred to in paleostress reconstructions by cataclastic analysis.

этой небольшой складки (таблица 1, 11630а и 11630b), поскольку им соответствовали разные локальные стресс-состояния.

Другие кинематические типы малых структур проявлены значительно слабее. Например, нам не удалось зафиксировать здесь стресс-стиллолитовые системы, а сдвиговые нарушения не образуют значимых максимумов на составленных по полевым замерам диаграммax.

Все полученные при расчетах данные по ориентировке главных осей и коэффициенту Лоде-Надаи сгруппированы в таблице 1. Для обработки методом катакластического анализа [Rebetsky, 2007] использованы собранные данные по тектоническим трещинам с определением кинематического типа на плоскости рассматриваемого дизъюнктива. Существенным оказался факт, что для выделения по этим данным локальных стресс-состояний в каждой из точек задействовано в среднем около 80 \% от числа сделанных в поле замеров. При этом использовано от 53 до 100 \% замеров от общего числа трещин со следами скольжения и от 63 до $100 \%$ от числа трещин со следами скольжения с определением геолого-кинематического типа перемещений. Таким образом, подавляющее число структурно-кинематических данных о трещинах обосновало выделение в каждой из точек единственного этапа деформирования. Выделение каких-либо других этапов деформирования в рамках метода катакластического анализа не потребовалось. Выделение обстановки северо-восточно - юго-западного растяжения здесь возможно (что показано выше) только при использовании данных геологических наблюдений и структурно-парагенетического анализа по другим малым структурным формам, так как либо более молодые трещины со следами более молодых подвижек отсутствуют, либо их доля в общей массе замеров не превышает 5-10 \%. Выделение из этих трещин генераций с «молодыми» смещениями в целом для всего района не проводилось и может быть вопросом для отдельного исследования. 


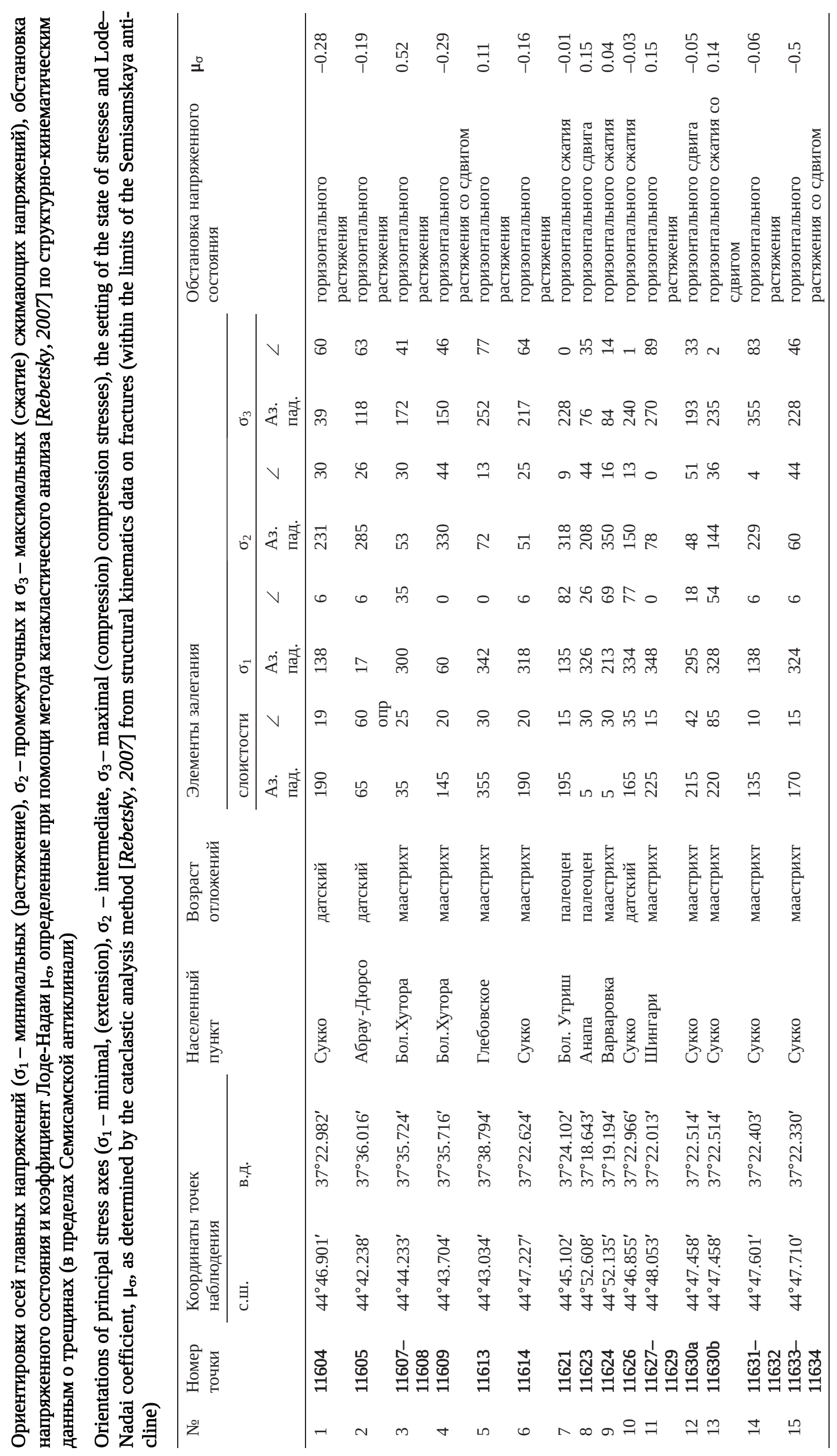




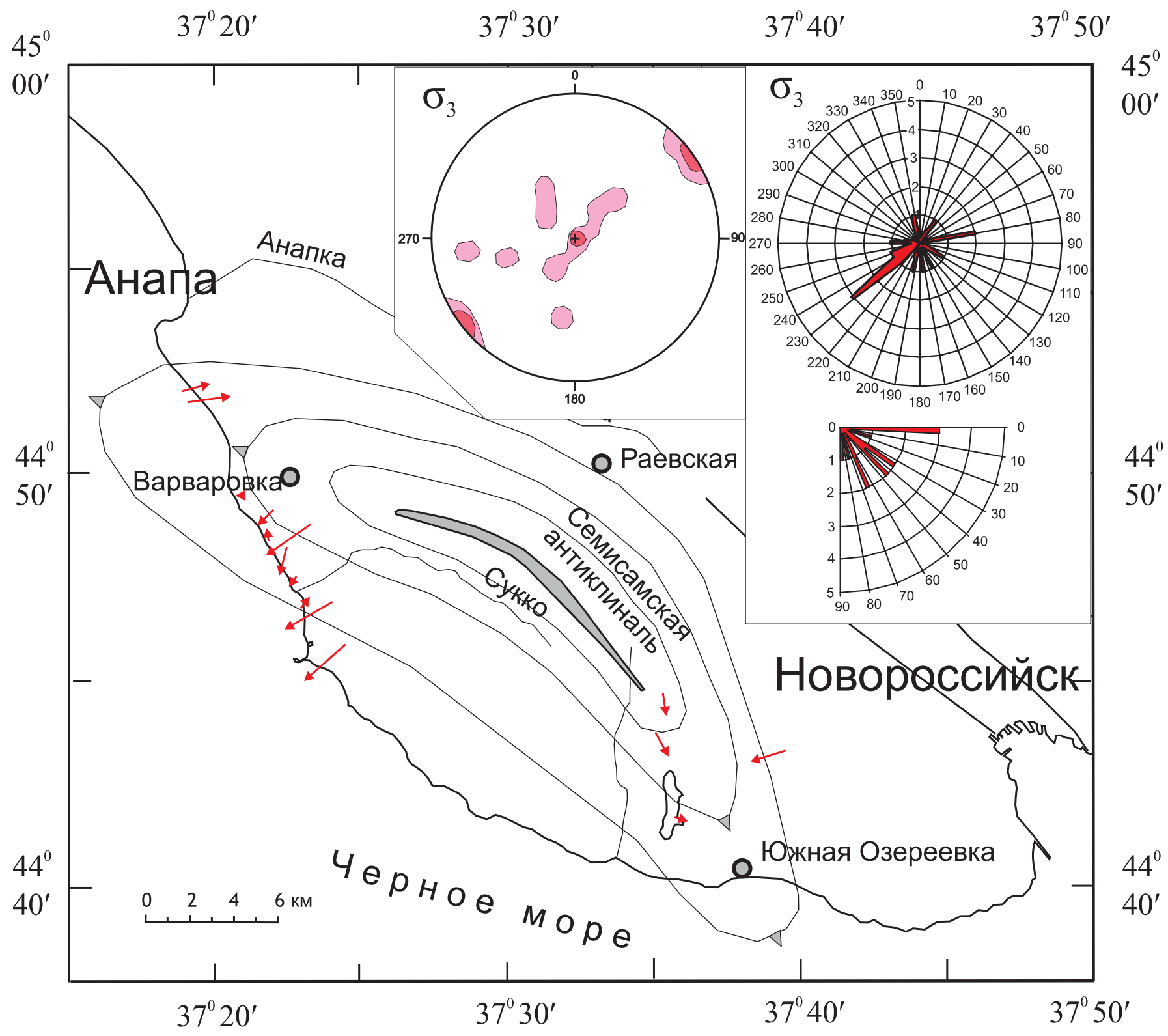

Рис. 15. Ориентировка осей максимальных сжимающих напряжений в пределах Семисамской антиклинали.

Стрелками красного цвета показаны проекции осей $\left(\sigma_{3}\right)$ максимальных сжимающих напряжений (направление стрелок в сторону погружения, их длина указывает на угол наклона оси - при вертикальном положении стрелки короткие, при горизонтальном - длинные). Врезка к карте. С левой стороны на круговой диаграмме (стереографическая проекция на верхнюю полусферу) показано плотностное распределение выходов осей максимальных сжимающих напряжений $\left(\sigma_{3}\right)$. С правой стороны расположены розы-диаграммы азимутов погружения (в верхней части) и углов наклона (внизу) максимальных (б$\sigma_{3}$ сжимающих напряжений (показано количество точек с определением локальных стресс-тензоров с шагом $10^{\circ}$ для азимутов погружения и с шагом $5^{\circ}$ для углов наклона).

Fig. 15. Orientations of maximum compression stress axes in the Semisamskaya anticline.

Red arrows show projections of maximum compression axes, $\sigma_{3}$ (arrow directions show directions of dipping; arrow lengths correspond to angles of inclination of the axes - short arrows correspond to vertical positions, long arrows to horizontal positions). Insert. At the left side of the circle diagram (stereographic projections to the upper hemisphere) - distribution of densities of output axes of maximum compression stresses, $\sigma_{3}$. At the right side - rose diagrams of dip azimuths (top) and inclination angles (bottom) of maximum compression stresses, $\sigma_{3}$ (the number of points with determined local stress tensors with $10^{\circ}$ spacing for dip azimuths and $5^{\circ}$ spacing for inclination angles). 


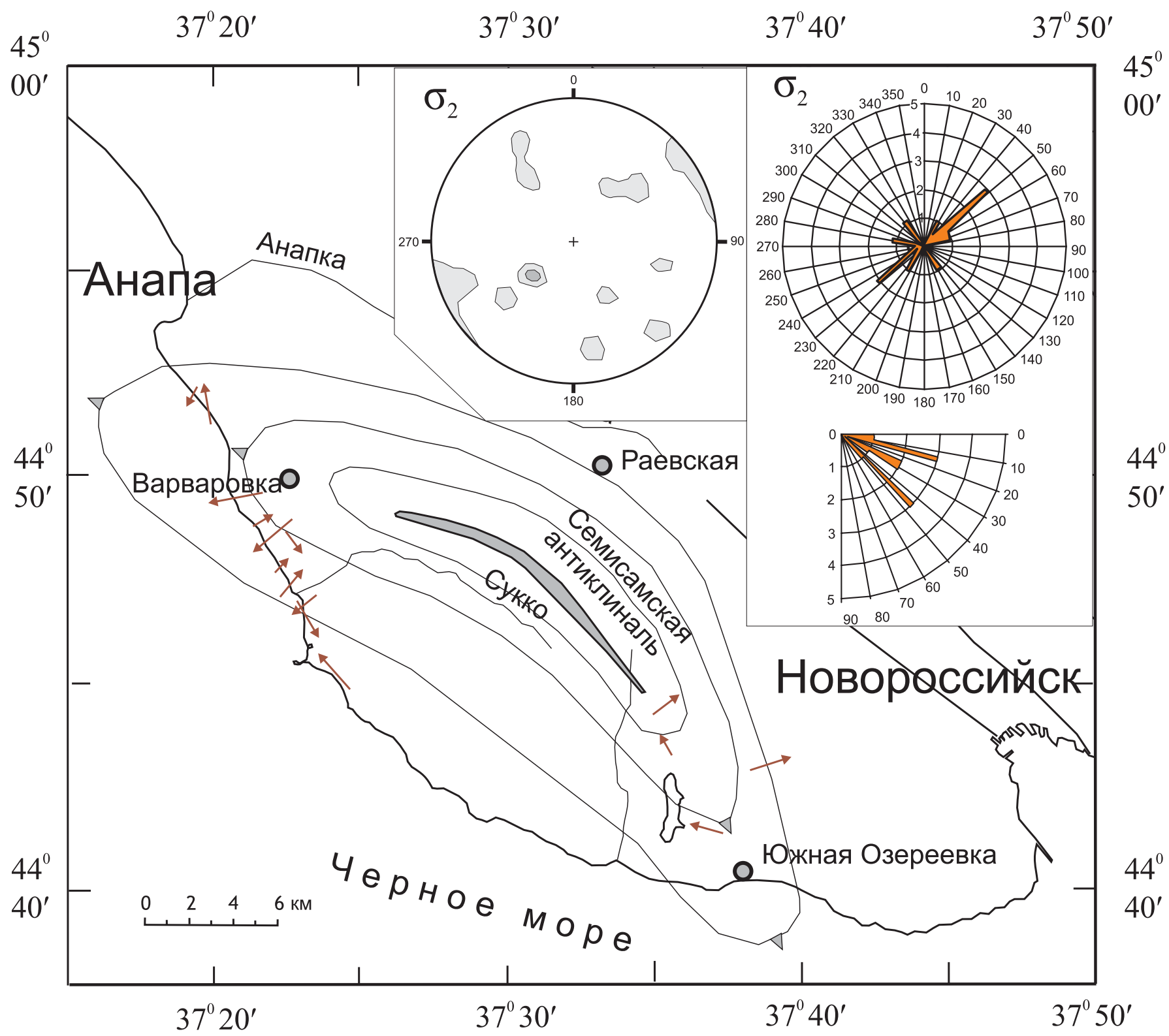

Рис. 16. Ориентировка осей промежуточных сжимающих напряжений в пределах Семисамской антиклинали.

Стрелками коричневого цвета показаны проекции осей $\left(\sigma_{2}\right)$ промежуточных сжимающих напряжений (направление стрелок в сторону погружения, их длина указывает на угол наклона оси - при вертикальном положении стрелки короткие, при горизонтальном - длинные). Врезка к карте. С левой стороны на круговой диаграмме (стереографическая проекция на верхнюю полусферу) показано плотностное распределение выходов осей промежуточных сжимающих напряжений $\left(\sigma_{2}\right)$. С правой стороны расположены розы-диаграммы азимутов погружения (в верхней части) и углов наклона (внизу) промежуточных $\left(\sigma_{2}\right)$ сжимающих напряжений (показано количество точек с определением локальных стресс-тензоров с шагом $10^{\circ}$ для азимутов погружения и с шагом $5^{\circ}$ для углов наклона).

Fig. 16. Orientations of intermediate compression stress axes in the Semisamskaya anticline.

Brown arrows show projections of intermediate compression axes, $\sigma_{2}$ (arrow directions show directions of dipping; arrow lengths correspond to angles of inclination of the axes - short arrows correspond to vertical positions, long arrows to horizontal positions). Insert. At the left side of the circle diagram (stereographic projections to the upper hemisphere) - distribution of densities of output axes of intermediate compression stresses, $\sigma_{2}$. At the right side - rose diagrams of dip azimuths (top) and inclination angles (bottom) of intermediate compression stresses, $\sigma_{2}$ (the number of points with determined local stress tensors with $10^{\circ}$ spacing for dip azimuths and $5^{\circ}$ spacing for inclination angles). 


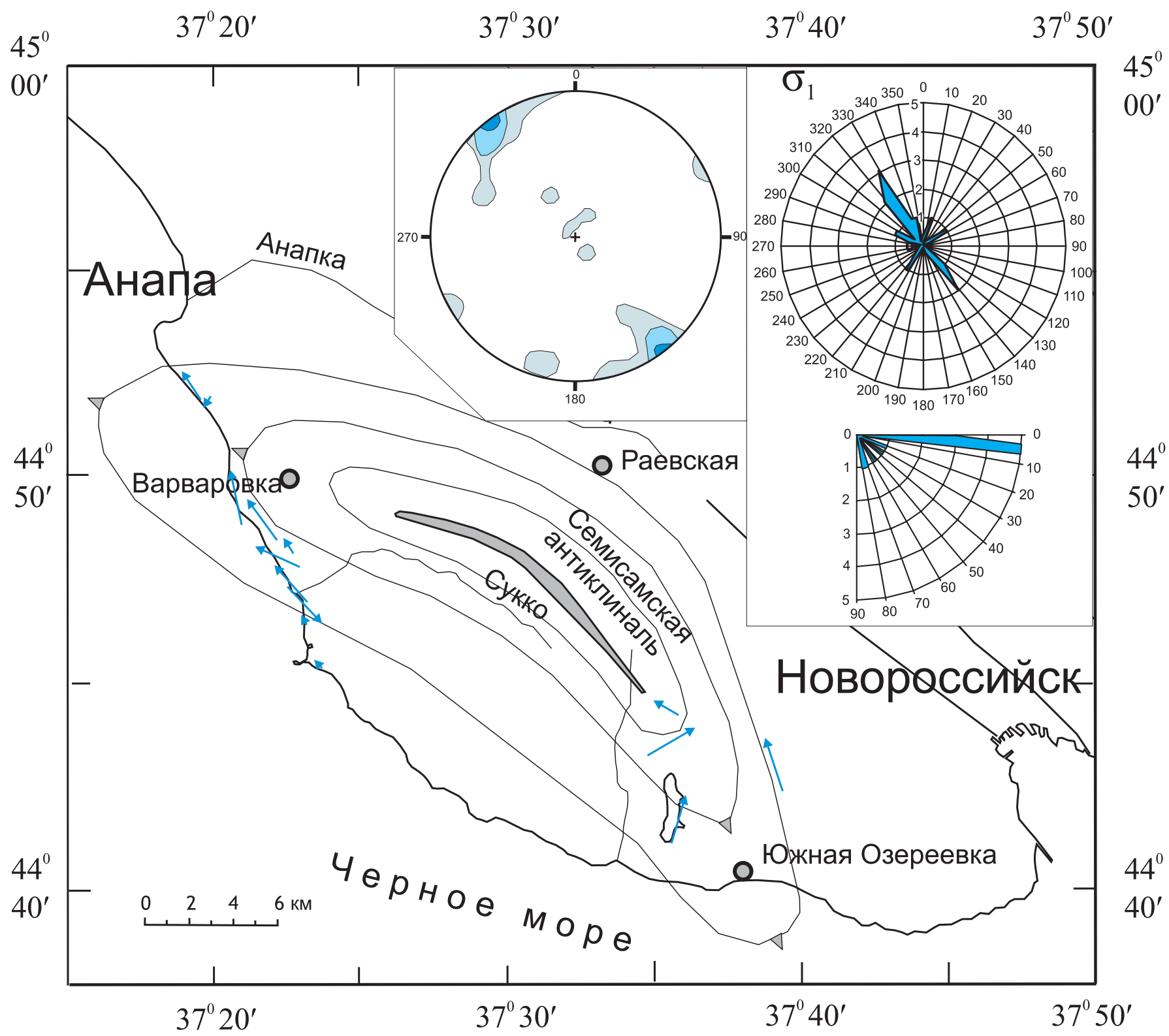

Рис. 17. Ориентировка осей минимальных сжимающих напряжений (девиаторное растяжение) в пределах Семисамской антиклинали.

Стрелками синего цвета показаны проекции осей $\left(\sigma_{1}\right)$ минимальных сжимающих напряжений (направление стрелок в сторону погружения, их длина указывает на угол наклона оси - при вертикальном положении стрелки короткие, при горизонтальном - длинные). Врезка к карте. С левой стороны на круговой диаграмме (стереографическая проекция на верхнюю полусферу) показано плотностное распределение выходов осей минимальных сжимающих напряжений $\left(\sigma_{1}\right)$. С правой стороны расположены розы-диаграммы азимутов погружения (в верхней части) и углов наклона (внизу) минимальных $\left(\sigma_{1}\right)$ сжимающих напряжений (показано количество точек с определением локальных стресс-тензоров с шагом $10^{\circ}$ для азимутов погружения и с шагом $5^{\circ}$ для углов наклона).

Fig. 17. Orientations of minimum compression stress axes in the Semisamskaya anticline.

Blue arrows show projections of minimum compression axes, $\sigma_{1}$ (arrow directions show directions of dipping; arrow lengths correspond to angles of inclination of the axes - short arrows correspond to vertical positions, long arrows to horizontal positions). Insert. At the left side of the circle diagram (stereographic projections to the upper hemisphere) - distribution of densities of output axes of minimum compression stresses, $\sigma_{1}$. At the right side - rose diagrams of dip azimuths (top) and inclination angles (bottom) of minimal compression stresses, $\sigma_{1}$ (the number of points with determined local stress tensors with $10^{\circ}$ spacing for dip azimuths and $5^{\circ}$ spacing for inclination angles). 


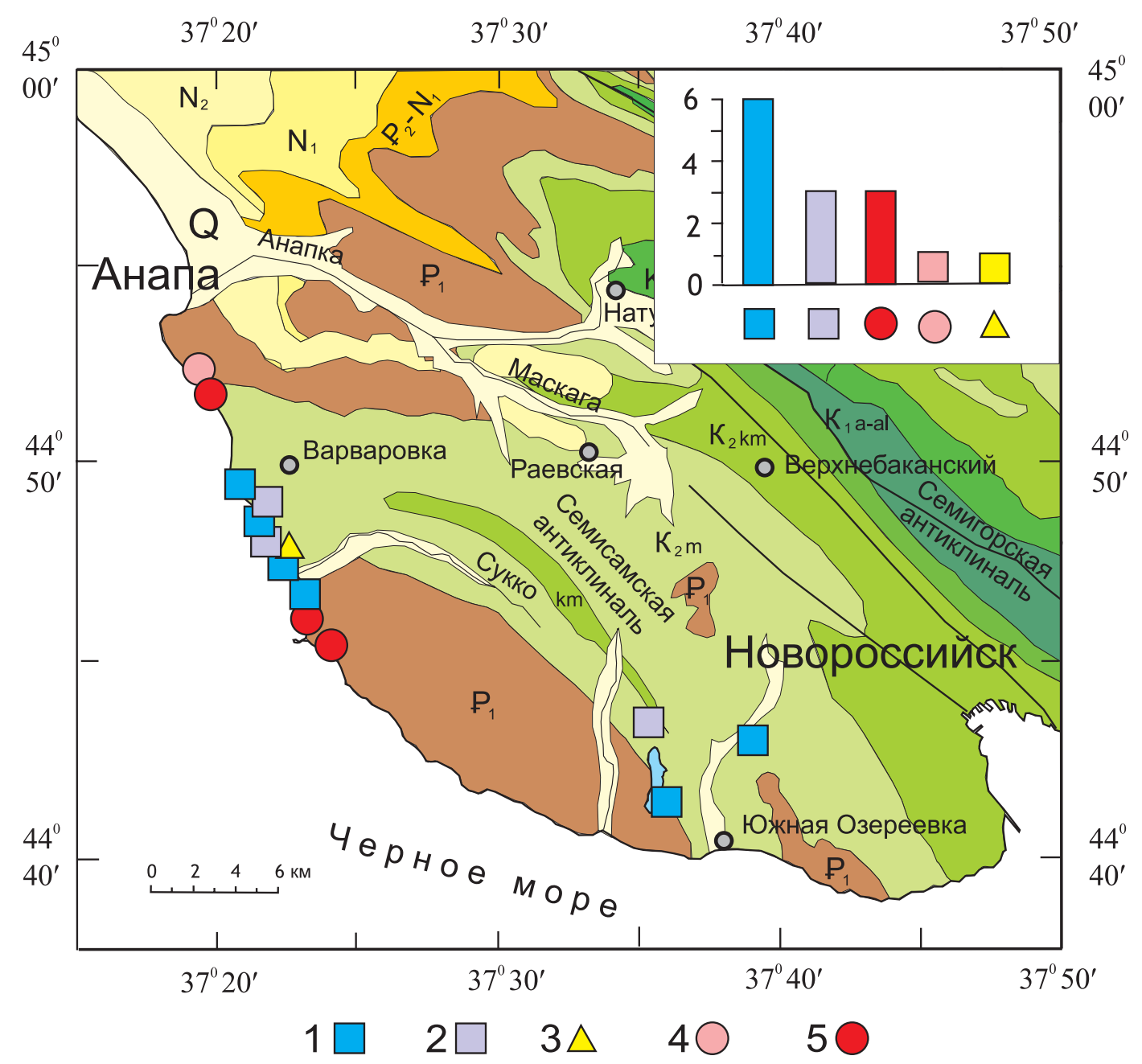

Рис. 18. Типы обстановок, определяемые в точках наблюдения с замерами трещин со структурно-кинематической информацией по пространственному положению реконструированных главных осей напряжения (согласно [Rebetsky, 2007]).

1 - горизонтальное растяжение; 2 - горизонтальное растяжение в сочетании со сдвигом; 3 - горизонтальный сдвиг; 4 - горизонтальное сжатие в сочетании со сдвигом; 5 - горизонтальное сжатие.

Fig. 18. Types of settings defined by taking into account the structural and kinematic information on the spatial position of the reconstructed principal stress axes (according to [Rebetsky, 2007]).

1 - horizontal extension; 2 - horizontal extension combined with shearing; 3 - horizontal shear; 4 - horizontal compression combined with shearing; 5 - horizontal compression.

По данным реконструкции методом катакластического анализа в разных частях Семисамской антиклинали выявлена значительная изменчивость ориентировок осей главных напряжений (рис. 15-17). В большинстве точек наблюдения определения коэффициента Лоде-Надаи приближаются к нулевому значению (от -0.15 до +0.15), что определяет состояниие простого сдвига.

Устанавливаются две преобладающие ориентировки осей максимальных сжимающих напряжений (см. рис. 15): северо-восточно - юго-западная (СВ-ЮЗ, азимут погружения Ю3 $230^{\circ}$, а угол погружения близок к нулю) и практически вертикальная (с отклонениями угла погружения до $60-70^{\circ}$ вдоль СВ-Ю3 направле- ния). Для осей промежуточных сжимающих напряжений (см. рис. 16) также характерна ориентировка в северо-восточном - юго-западном направлении (но уже с преимущественным погружением по азимуту СВ $50^{\circ}$ и углом 45-50²). Зафиксировано также слабопроявленное северо-западное - юго-восточное направление (C3 330 ${ }^{\circ}$.

Оси минимальных сжимающих напряжений (девиаторного растяжения) очень четко ориентированы в северо-западно - юго-восточном направлении (азимут погружения С3 320-330 с углом погружения, близким к нулю). Причем, если для разных частей Семисамской антиклинали характерны вариации и смена положения осей сжатия $\left(\sigma_{3}\right)$ и промежуточной $\left(\sigma_{2}\right)$, то ориенти- 

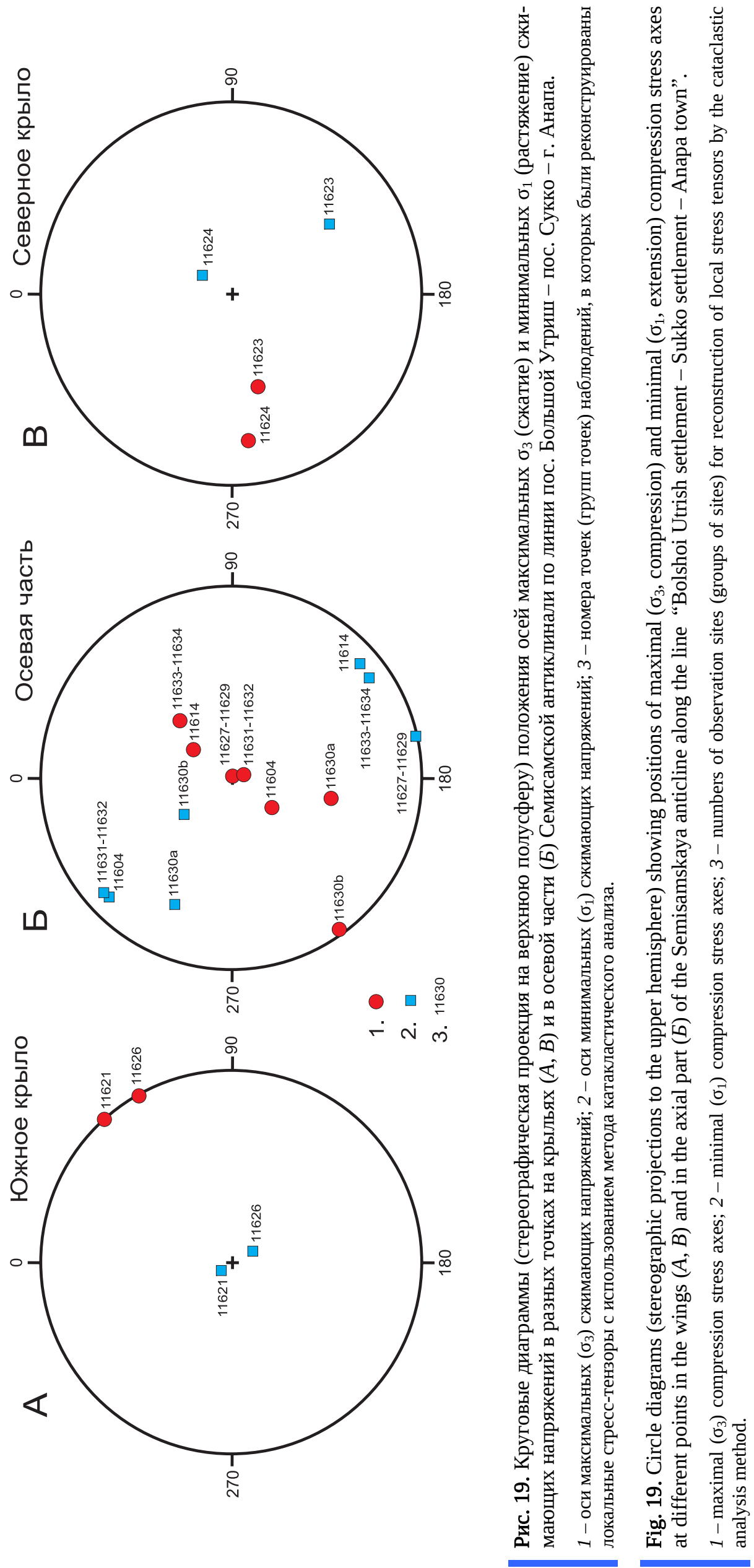


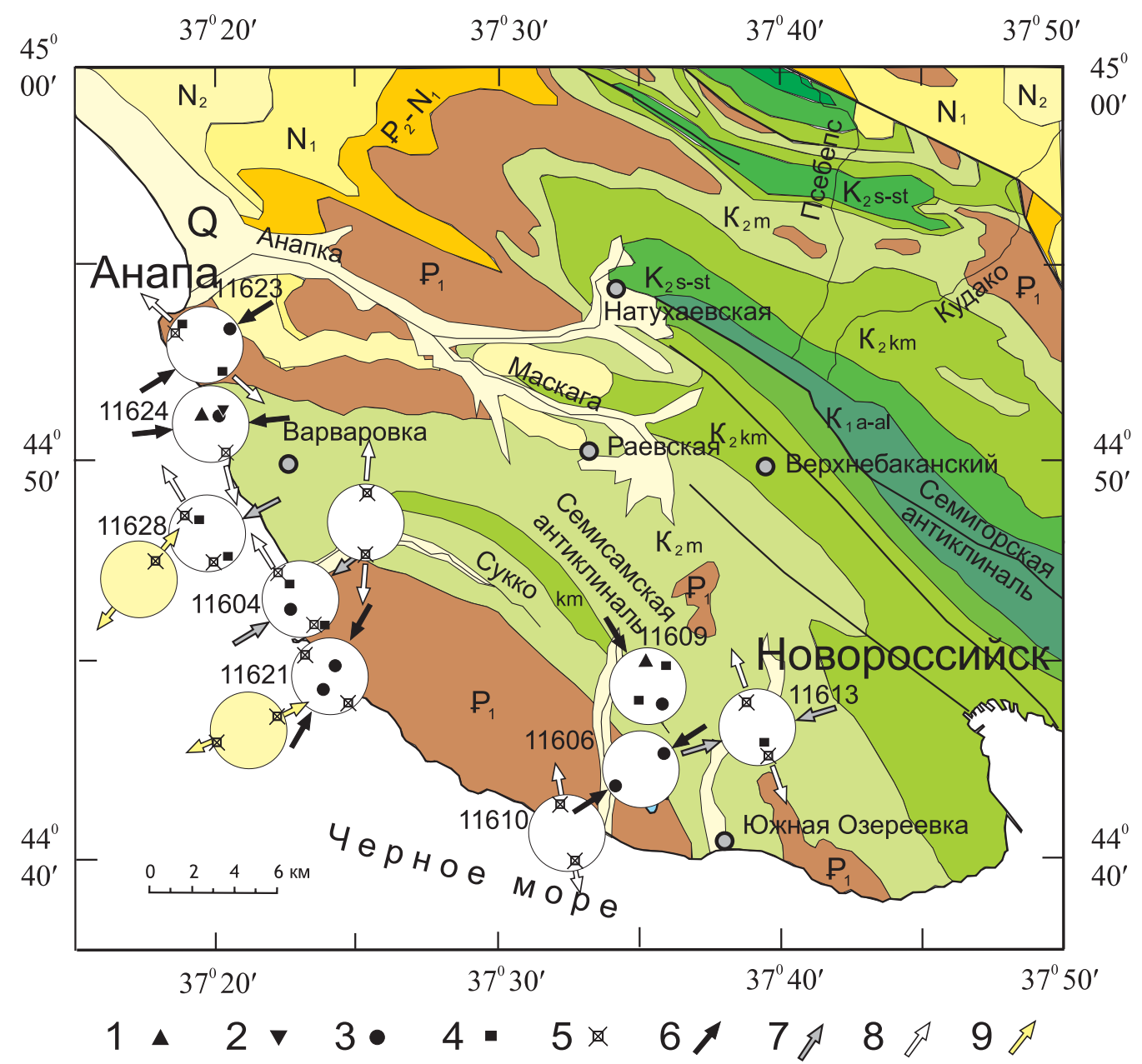

Рис. 20. Ориентировка осей максимальных сжимающих напряжений в пределах Семисамской антиклинали (определенных при помощи метода структурно-парагенетического анализа).

На круговых диаграммах (стереографическая проекция на верхнюю полусферу) показаны полюсы наиболее проявленных систем тектонических трещин с преимущественным типом смещения: 1 -правосдвиговым, 2 -левосдвиговым, 3 - сбросовым, 4-взбросо-надвиговым и 5 - отрывно-раздвиговым. Рядом с круговыми диаграммами стрелками показаны ориентировки осей: 6 - максимальных ( $\left.\sigma_{3}\right)$ сжимающих напряжений (черная заливка), 7 - промежуточных $\left(\sigma_{2}\right)$ сжимающих напряжений (серая заливка), 8 - минимальных ( $\left.\sigma_{1}\right)$ сжимающих напряжений (без заливки), 9 - минимальных $\left(\sigma_{1}\right)$ сжимающих напряжений (девиаторного растяжения) хронологически более позднего этапа (желтая заливка).

Fig. 20. Orientations of maximal compression stress axes within the limits of the Semisamskaya anticline (determined by the structural paragenesis method).

Circle diagrams (stereographic projections to the upper hemisphere) show poles of the most evidently manifested systems of tectonic fractures and dominant displacement types: 1 - right-side shear; 2 - left-side shear; 3 - normal fault; 4 - thrust with reverse component; 5 - spreading joint. Arrows at the circle diagrams show orientations of the axes: 6 - maximal $\left(\sigma_{3}\right)$ compression stress (black); 7 -intermediate $\left(\sigma_{2}\right)$ compression stress (grey); 8 -minimal $\left(\sigma_{1}\right)$ compression stress (no colour); 9 -minimal $\left(\sigma_{1}\right)$ compression stress (deviatoric extension) of the chronologically later stage (yellow).

ровка оси $\sigma_{1}$ в основном имеет выдержанный характер (рис. 17).

Значительная изменчивость по площади установлена нами и для обстановок, определяемых с помощью метода катакластического анализа по пространственному положению реконструированных главных осей напряжений (типы обстановок приводятся согласно [Rebetsky, 2007]). Наиболее распространенной здесь является обстановка горизонтального растяжения при субвертикальном положении оси $\left(\sigma_{3}\right)$ максимальных сжимающих напряжений и субгоризонтальном положении оси $\left(\sigma_{1}\right)$ минимальных сжимающих напряжений (рис. 18). Реже фиксируются обстановки горизонтального сжатия ( $\sigma_{3}-$ субгоризонтальна, $\sigma_{1}-$ субвертикальна), горизонтального растяжения в сочетании со сдвигом и горизонтального сдвига (оси $\sigma_{1}$ и $\sigma_{3}$ имеют близгоризонтальное положение). При этом в приосевой части складки преобладают обстановки горизонтального растяжения и горизонтального растяжения в сочетании со сдвигом, а на крыльях антиклинали опре- 
деляются обстановки горизонтального сжатия и горизонтального сдвига (рис. 19). Единственные выделенные в приосевой части Семисамской антиклинали в точке наблюдения 11630 условия горизонтального сжатия в сочетании со сдвигом и горизонтального сдвига приурочены к небольшой осложняющей складке, на крыльях которой и были выполнены замеры.

Некоторые полученные результаты полевых тектонофизических исследований могут иметь несколько вариантов интерпретации и требуют дальнейшего уточнения. Так, многочисленные сбросо-отрывные нарушения могут быть поверхностным проявлением Анапской и Джигинской флексурно-разломных зон (Ю3-СВ простирания). Складчатые структуры СевероЗападного Кавказа испытывают здесь флексурообразный перегиб и западнее изученного участка они погружаются, перекрываясь более молодыми отложениями Керченско-Таманского поперечного прогиба. Другой вариант связан с удлинением вдоль оси складчатого сооружения. При этом ось максимального девиаторного растяжения, которая по полученным данным ориентирована субгоризонтально в направлении C3 $320^{\circ}$, совпадает с простиранием основных складчатых структур.

Более молодой режим северо-восточного (СВ 70) девиаторного растяжения также имеет несколько возможных объяснений, которые уже были ранее высказаны разными исследователями [Saintot, Angelier, 2002; Marinin, 2003; Marinin, Saintot, 2012]. Во-первых, это может быть связано с разваливанием горного сооружения Северо-Западного Кавказа после его поднятия в сторону Черноморской впадины и ЗападноКубанского прогиба. Возможным объяснением может быть и связь этого растяжения с действием северосеверо-западного сжатия, которое хорошо проявлено в молодых миоценовых отложениях. Однако здесь это направление сжимающих напряжений не нашло представительного подтверждения. То есть в момент проявления более позднего северо-северо-западного сжатия исследованный район представлял уже достаточно «жесткий» блок и влияние более поздних стрессов мы можем определить в молодых отложениях соседних «менее жестких» блоков или в зонах новейших разрывных нарушений. Согласно же неотектоническим построениям С.А. Несмеянова, исследованный район целиком принадлежит Абраусскому поднятию Баканского брахисвода [Nesmeyanov, 1992], и мы можем видеть проявления более поздних стресс-режимов только в зоне Утришского и Западноутришского сброса, где нами определены условия северо-восточного растяжения (рис. 20).

\section{4. ЗАКЛЮЧЕНИЕ}

Проведенные тектонофизические исследования в пределах области, занимаемой Семисамской антикли- налью, впервые позволили установить здесь существенные изменения в ориентации главных осей, связанных с одним временным интервалом деформирования - эпохой складкообразования, под которой мы понимаем весь сложный парагенез пликативных и дизъюнктивных нарушений, приводящий к оформлению складчатого сооружения. Полученные данные говорят о преобладании по направлению северо-восток - югозапад погружений осей максимальных и промежуточных сжимающих напряжений с существенными вариациями углов их погружения (в отличие от установленного ранее для этой части Северо-Западного Кавказа субгоризонтального северо-восточного сжатия). В приосевой части антиклинали ось максимальных сжимающих напряжений $\left(\sigma_{3}\right)$ занимает вертикальное положение, а сжатие поперек складчатой структуры здесь обеспечивает промежуточная ось главных напряжений $\left(\sigma_{2}\right)$. Заметную роль, таким образом, здесь играет субвертикальное укорочение в приосевой части и удлинение в северо-западно - юго-восточном направлении, а укорочение в северо-восточно - юго-западном направлении здесь меньше, нежели на крыльях антиклинали, где оси максимальных сжимающих напряжений приобретают горизонтальное положение.

Мы можем сделать вывод о более сложном механизме формирования складчатых структур СевероЗападного Кавказа, по сравнению с рассматриваемым в большинстве современных работ вариантом с общим укорочением поперек складчатого сооружения. Укорочение по направлению северо-восток - юго-запад в широкой приосевой области складки было меньше, нежели укорочение в субвертикальном направлении, что может быть связано с гравитационной нагрузкой вышележащих толщ или с силами различного генезиса, направленными снизу.

Таким образом, полученные данные по характеру распределения главных напряжений позволили прояснить действующие здесь два основных механизма формирования складчатой структуры: вертикальное расплющивание с субвертикальной осью максимальных сжимающих напряжений и горизонтальное продольное сжатие с субгоризонтальной северо-восточной ориентировкой оси максимальных сжимающих напряжений. Для территории, занимаемой антиклиналью, характерна закономерная смена условий напряженного состояния от горизонтального растяжения до горизонтального сжатия с наличием переходных типов.

В пределах Семисамской антиклинали установлена относительная хронология деформационных событий, регистрируемых по структурно-кинематических данным о трещинах. Этап, выделенный по трещинам с установленной кинематикой смещений, по нашим данным, является не самым последним и относится преимущественно ко времени развития складчатого сооружения. Признаки более «молодых» этапов сосредоточены на границах неотектонических структур (например, подобно отрывам и раздвигам в зоне Утриш- 
ского сброса).

Проведенные исследования также позволили нам сделать следующие выводы по практике полевых тектонофизических работ в пределах складчатых сооружений.

Использование метода катакластического анализа по структурно-кинематическим данным о трещинах на примере части складчатого сооружения. С помощью метода катакластического анализа нами детально определены локальные стресс-состояния в разных точках исследованного района. Для их определения понадобилось существенно меньше замеров по трещинам с установленным характером смещений, чем для корректного определения по типовым рисункам в структурно-парагенетическом методе. При этом не потребовалось объединения частных диаграмм по отдельным точкам в группы диаграмм, что зачастую ведет к усложнению картины напряженного состояния, не обусловленного природными данными.

Пространственные вариации локальных стресссостояний в пределах складчатого сооружения. Распределение полученных стресс-тензоров показывает существенные вариации единого поля напряжений, связанного с формированием складчатого сооружения. При полевых тектонофизических исследованиях следует учитывать возможные изменения параметров локальных стресс-состояний даже в пределах одного участка или обнажения, особенно если между площадками замеров есть зоны пликативных или дизъюнктивных нарушений.

Пространственно-временные соотношения определяемых локальных стресс-тензоров по структурно- кинематическим данным о трещинах. При детальном изучении складчатой структуры с помощью метода катакластического анализа определялись в основном пространственные вариации единого поля напряжений. В рассмотренных точках не выделялись хронологически обособленные стресс-режимы, поскольку при расчетах для каждой из точек наблюдения процент использованных замеров для определения локального стресс-состояния составлял от 65 до $100 \%$. Однако для выявления признаков действия «более слабых» тензоров напряжения и установления хронологической последовательности эффективно было дополнение выполненных исследований обычными структурногеологическими наблюдениями и методом структурнопарагенетического анализа (рис. 20), которые позволили установить здесь многоэтапность режима северозападного растяжения и режим более позднего северовосточного растяжения.

\section{5. БЛАГОДАРНОСТИ}

Автор выражает искреннюю благодарность сотрудникам тектонофизического отряда ИФЗ РАН Л.А. Сим и Р.С. Алексееву, с которыми совместно собран материал для данного исследования, а также всем своим коллегам по работе в ИФЗ РАН и МГУ - Л.М. Расцветаеву, Т.Ю. Тверитиновой, Ю.Л. Ребецкому и А.В. Михайловой, чьи советы и замечания способствовали подготовке данной статьи. Мы также благодарны РФФИ, при финансовой поддержке которого были проведены полевые работы (проект № 12-05-10059к).

\section{6. ЛИТЕРАTУРА / REFERENCES}

Afanasenkov A.P., Nikishin A.M., Obukhov A.N. Eastern Black Sea Basin: Geological Structure and Hydrocarbon Potential. Publ. Scientific World (Nauchnyi mir), Moscow, 172 p. (in Russian) [Афанасенков А.П., Никишин А.М., Обухов А.Н. Геологическое строение и углеводородный потенциал Восточно-Черноморского региона. М.: Научный мир, 2007. 172 c.].

Chang C.-P. , Angelier J. , Lee T.-Q., Huang C.Y., 2003. From continental margin extension to collision orogen: structural development and tectonic rotation of the Henchun peninsula Taiwan // Tectonophysics 361 (1-2), 61-82. http://dx.doi. org/10.1016/S0040-1951(02)00561-9.

Leonov Yu.G., Gushchenko O.I., Kopp M.L., Rastsvetaev L.M., 2001. Relationship between the Late Cenozoic stresses and deformations in the Caucasian sector of the Alpine belt and its Northern foreland. Geotectonics 35 (1), 30-50.

Marinin A.V., 2003. Features of the tectonic structure of Seversky and Psekupsky blocks (North-West Caucasus). Bulletin of Moscow Society of Naturalists (Geological Series) 2, 22-24 (in Russian) [Маринин А.В. Особенности тектонического строения Северской и Псекупской ступеней (Северо-Западный Кавказ) // Бюллетень МОИП, Отделение геологии. 2003. № 2. С. 22-24].

Marinin A.V., Rastsvetaev L.M., 2008. Tectonic structures of the North-West Caucasus. Tectonophysics and actual problem of Earth sciences. In: Problems of Tectonophysics. The 40th anniversary of M.V. Gzovsky Laboratory of Tectonophysics in IPE RAS. IPE RAS, Moscow, p. 191-224 (in Russian) [Маринин А.В., Расцветаев Л.М. Структурные парагенезы Северо-Западного Кавказа // Проблемы тектонофизики. К 40-летию создания М.В. Гзовским лаборатории тектонофизики в ИФЗ РАН. М.: ИФЗ, 2008. С. 191-224].

Marinin A.V., Saintot A., 2012. Comparison of methods to reconstruct paleostress regimes in the NW-Greater Caucasus foldand-thrust belt. Comptes Rendus Geoscience 344 (3), 181-190. http://dx.doi.org/10.1016/j.crte.2012.01.004.

Nesmeyanov S.A., 1992. Neotectonics Zoning of the North-West Caucasus. Nedra, Moscow, 254 p. (in Russian) [Несмеянов С.А. Неоструктурное районирование Северо-Западного Кавказа. М.: Недра, 1992. 254 с.].

Nikolaev P.N., 1992. The Method of Tectonodynamic Analysis. Nedra, Moscow, 295 p. (in Russian) [Николаев П.Н. Методика тектонодинамического анализа. М.: Недра, 1992. 295 с.].

Rastsvetaev L.M., 1977. The Mountainous Crimea and Northern Black Sea Area. In: Faults and Horizontal Movements of 
Mountain Chains in the USSR. Nauka, Moscow, p. 95-113 (in Russian) [Расцветаев Л.М. Горный Крым и Северное Причерноморье // Разломы и горизонтальные движения горных сооружений СССР. М.: Наука, 1977. С. 95-113].

Rastsvetaev L.M., 1987. The paragenetic method of structural analysis of tectonic faults. In: Problems of structural geology and physics of tectonic faults. Publishing House of GIN, the USSR Academy of Science, Moscow, Part 2, P. $173-235$ (in Russian) [Расцветаев Л.М. Парагенетический метод структурного анализа дизъюнктивных тектонических нарушений // Проблемы структурной геологии и физики тектонических процессов. М.: ГИН АН СССР, 1987. Ч. 2. C. 173-235].

Rastsvetaev L.M., Korsakov S.G., Tveritinova T.Yu., Semenukha I.N., Marinin A.V., 1999. On certain common features of the structure and tectodynamics of the North-West Caucasus. In: Problems of geology, mineral resource base and ecology of South Russia and Caucasus. Novocherkassk, Vol. 1, P. 69-73 (in Russian) [Расцветаев Л.М., Корсаков С.Г., Тверитинова Т.Ю., Семенуха И.Н., Маринин А.В. О некоторых общих особенностях структуры и тектодинамики Северо-Западного Кавказа // Проблемы геологии, полезных ископаемых и экологии юга России и Кавказа. Новочеркасск, 1999. Т. 1. С. 69-73].

Rebetsky Y.L., 2007. Tectonic Stresses and Strength of Rocks. Nauka, Moscow, 406 p. (in Russian) [Ребецкий Ю.Л. Тектонические напряжения и прочность горных массивов. М.: Наука, 2007. 406 с.].

Saintot A., Angelier J., 2002. Tectonic paleostress fields and structural evolution of the NW-Caucasus fold-and-thrust belt from Late Cretaceous to Quaternary. Tectonophysics 357 (1-4), 1-31. http://dx.doi.org/10.1016/S0040-1951(02)00360-8.

Shcheglov A.P., Chekunov V.A., 1991. Late orogenic stage in the history of tectonic evolution of the southern slope of the NW-Caucasus (between Gelendzhik town and Abrau village). In: Mechanisms of structure formation in the lithosphere and seismicity. IPE RAS, Moscow, p. 78-79 (in Russian) [Щеглов А.П., Чекунов В.А. Позднеорогенная стадия в истории тектонического развития южного склона Северо-Западного Кавказа (между г. Геленджиком и пос. Абрау) // Механизмы структурообразования в литосфере и сейсмичность: Тез. докл. Всесоюзн. симпоз. М.: ИФЗ АН CCCP, 1991. C. 78-79].

Viginsky V.A., 1986. The Recent Structure of the Western Part of the Caucasus and the Adjacent Territory of the North Caucasus and its Manifestation in Geophysical Fields. Synopsis of $\mathrm{PhD}$ Thesis (Candidate degree in geology and mineralogy). Publishing House of IPE, the USSR Academy of Science, Moscow, 18 p. (in Russian) [Вигинский В.А. Новейшая структура западной части Кавказа и прилегающего Предкавказья и ее выражение в геофизических полях: Автореф. дис. ... канд. геол.-мин. наук. М.: ИФЗ АН СССР, 1986. 18 с.].

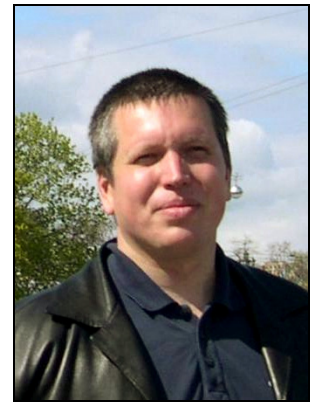

Маринин Антон Витальевич, канд. геол.-мин. наук, с.н.с.

Институт физики Земли им. О.Ю. Шмидта РАН

123995, ГСП-5, Москва, ул. Большая Грузинская, д. 10, стр. 1

$\triangle$ e-mail: marinin@yandex.ru

Marinin, Anton V., Candidate of Geology and Mineralogy, Senior Researcher

The Schmidt Institute of Physics of the Earth RAS

10 Bolshaya Gruzinskaya street, Moscow 123995, Russia

凶e-mail: marinin@yandex.ru 